Review

\title{
Lipid bilayer stress in obesity-linked inflammatory and metabolic disorders
}

\author{
Marco A. Gianfrancesco ${ }^{\mathrm{a}, \mathrm{b}}$, Nicolas Paquot ${ }^{\mathrm{a}, \mathrm{b}}$, Jacques Piette ${ }^{\mathrm{c}}$, Sylvie Legrand-Poels ${ }^{\mathrm{a}, \mathrm{c}, *}$ \\ ${ }^{a}$ Laboratory of Immunometabolism and Nutrition, GIGA-I3, University of Liège, Liège, Belgium \\ ${ }^{\mathrm{b}}$ Division of Diabetes, Nutrition and Metabolic Disorders, Department of Medicine, University Hospital of Liège, Liège, Belgium \\ ${ }^{c}$ Laboratory of Virology and Immunology, GIGA-Molecular Biology of Diseases, University of Liège, Liège, Belgium
}

\section{A R T I C L E I N F O}

\section{Keywords:}

Membrane

Lipid

ER stress

Metabolism

Obesity

\begin{abstract}
A B S T R A C T
The maintenance of the characteristic lipid compositions and physicochemical properties of biological membranes is essential for their proper function. Mechanisms allowing to sense and restore membrane homeostasis have been identified in prokaryotes for a long time and more recently in eukaryotes. A membrane remodeling can result from aberrant metabolism as seen in obesity. In this review, we describe how such lipid bilayer stress can account for the modulation of membrane proteins involved in the pathogenesis of obesity-linked inflammatory and metabolic disorders. We address the case of the Toll-like receptor 4 that is implicated in the obesity-related low grade inflammation and insulin resistance. The lipid raft-mediated TLR4 activation is promoted by an enrichment of the plasma membrane with saturated lipids or cholesterol increasing the lipid phase order. We discuss of the plasma membrane $\mathrm{Na}$, K-ATPase that illustrates a new concept according to which direct interactions between specific residues and particular lipids determine both stability and activity of the pump in parallel with indirect effects of the lipid bilayer. The closely related sarco(endo)-plasmic Ca-ATPase embedded in the more fluid ER membrane seems to be more sensitive to a lipid bilayer stress as demonstrated by its inactivation in cholesterol-loaded macrophages or its inhibition mediated by an increased PtdCho/PtdEtn ratio in obese mice hepatocytes. Finally, we describe the model recently proposed for the activation of the conserved IRE-1 protein through alterations in the ER membrane lipid packing and thickness. Such IRE- 1 activation could occur in response to abnormal lipid synthesis and membrane remodeling as observed in hepatocytes exposed to excess nutrients. Since the IRE-1/XBP1 branch also stimulates the lipid synthesis, this pathway could create a vicious cycle "lipogenesis-ER lipid bilayer stress-lipogenesis" amplifying hepatic ER pathology and the obesitylinked systemic metabolic defects.
\end{abstract}

Cellular membranes are highly organized structures mainly composed of lipids. Different types of proteins facilitating cellular functions and adaptation to stress are also found into lipid membranes, including both integral and peripheral membrane proteins. The original fluid mosaic model of biological membranes was introduced 40 years ago by Singer and Nicolson describing some globular integral membrane proteins and glycoproteins free to diffuse laterally in the fluid lipid membrane plane [1]. This model is still currently applicable for most experimental conditions but additional informations such as protein and lipid aggregations into domains, cytoskeleton and extracellular matrix interactions are now part of a deeper view of membrane regulation and hierarchy. Besides heterogeneity of membrane domains, forces that dictate membrane curvature, deformation and expansion add complexity to the dynamic of lipidic structures in constant remodeling to assume their biological functions. The amphiphilic properties of lipids permit them to self-assemble creating micelles or bilayers. Water forms a hydrogen bond cage on the surface of the hydrophilic head groups of lipids while their hydrophobic tails are protected [2]. This property not only allows cells to create a wall between internal constituents and external environment, but also to delineate internal compartments and restricted places where chemical reactions are taking place to increase biochemical efficiency [3].

Biological membranes are functionalized by the embedding of membrane proteins that act as receptors, transporters, channels, enzymes and structural elements. Many crucial signaling processes occur at membrane surfaces. Moreover, a specific membrane composition confers a proper function on each organelle. Therefore, cells are equipped with surveillance systems to maintain membrane homeostasis. Lipids have key roles in membrane remodeling processes. Accordingly, their biosynthesis has to be tightly regulated.

In this review, we will start by describing the structure, the physicochemical properties and the synthesis pathways of the main structural lipids of eukaryotic membranes. This first part will allow a better understanding of both the mechanisms and consequences of membrane

\footnotetext{
* Corresponding author at: Laboratory of Immunometabolism and Nutrition, GIGA-I3, University of Liège, Liège, Belgium.

E-mail address: s.legrand@uliege.be (S. Legrand-Poels).
} 
A

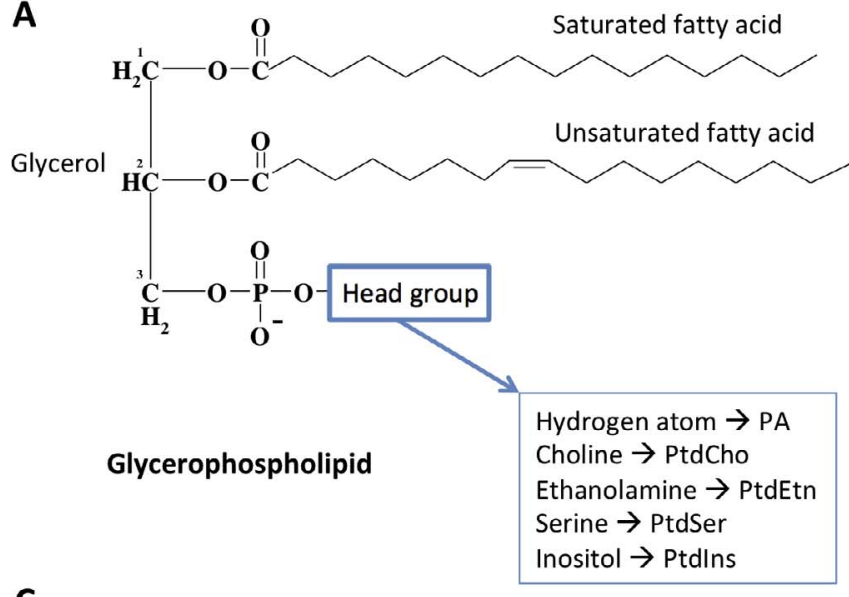

C

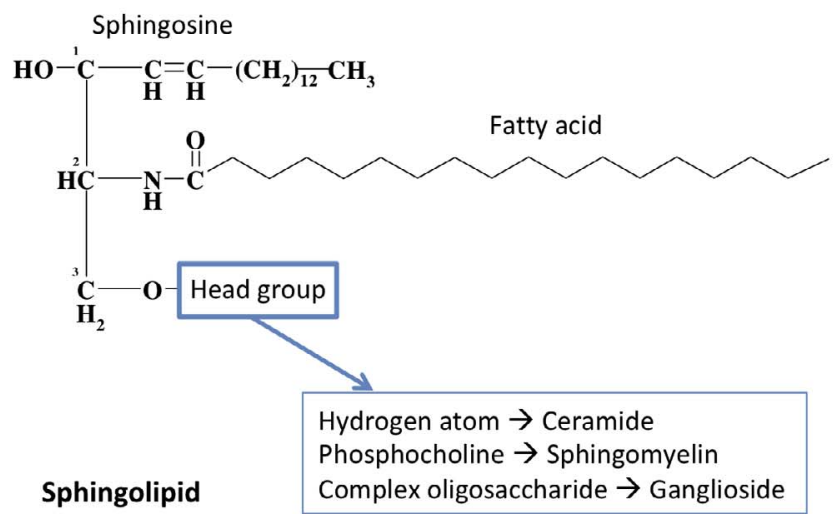

B

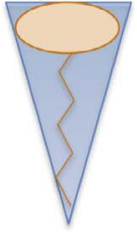

Lysophospholipids e.g. LPA and LPC

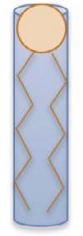

PtdCho

PtdSer

Ptdlns

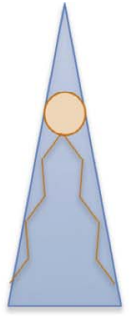

PtdEtn

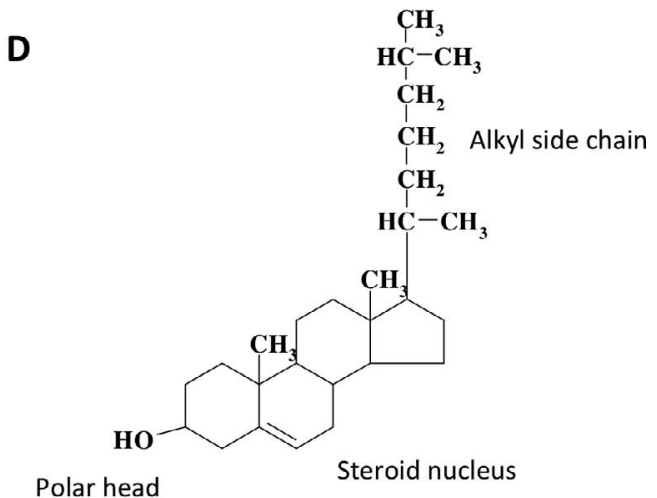

Cholesterol

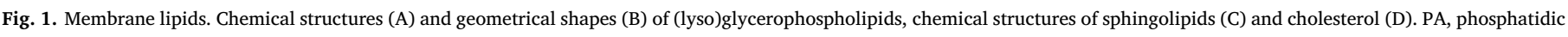

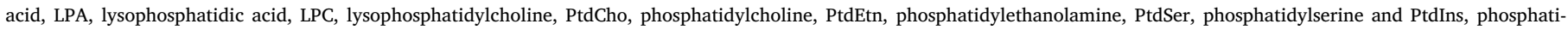
dylinositol.

remodeling that occurs in some circumstances like in obesity-related metabolic disorders. In the second part, we will focus on some membrane proteins whose function is modulated by lipid bilayer modifications. Finally, we will review mechanisms developed in prokaryotes and eucaryotes to sense and restore membrane fluidity. We will put the emphasis on the underlying physicochemical mechanisms and on the relevance in obesity-linked inflammatory and metabolic disorders.

\section{Membrane composition and structure}

\subsection{Membrane lipids}

\subsubsection{Glycerophospholipids}

The glycerophospholipids are the building blocks of cellular membranes. They are characterized by an amphipathic structure with a hydrophobic tail composed of two fatty acyl chains ester bond-linked to positions 1 and 2 (sn-1 and -2) of a glycerol backbone and a hydrophilic head group consisting of a phosphate group linked to position 3 (sn-3) of the glycerol with a phosphodiester bond (Fig. 1A) [4]. The phosphatidic acid (PA) is the most basic structure and an important intermediate in the synthesis of glycerophospholipids that carry an additional group attached to the phosphate. According to the nature of this head group, glycerophospholipids can be divided into four classes: phosphatidylcholine (PtdCho), phosphatidylethanolamine (PtdEtn), phosphatidylinositol (PtdIns), phosphatidylserine (PtdSer) (Fig. 1A). Variations in head groups and aliphatic chains of lipids permit the eukaryotic cell to reach more than 1000 different lipid species with only $5 \%$ of the cell genes involved [5]. The head group of PtdCho and PtdEtn is zwitterionic while the one of PtdIns and PtdSer is anionic. In mammalian cells, the PtdCho reach up to 55\% of total lipids while PtdEtn,
PtdIns and PtdSer count for 15-25\%, 10-15\% and 5-10\%, respectively $[6]$.

PtdCho's cylindrical molecular geometry permits them to self-assemble automatically into bilayers (Fig. 1B). The PtdEtn conical shape imposes curvature stresses on the membrane (Fig. 1B) $[7,8]$. The nonbilayer propensity of PtdEtn eases the membrane fusion and binding of peripheral membrane proteins $[7,8]$. Anionic lipids such as PtdSer and PtdIns are implicated in membrane charge and facilitate the interactions with positively charged domains of peripheral and integral membrane proteins $[9,10]$. The term "lyso" refers to the glycerolipids/ glycerophospholipids carrying only one acyl chain. They have a large hydrophilic head group compared to their hydrophobic tail. These lipids tend to pack in highly curved structures (Fig. 1B) [11]. In addition to lysophosphatidic acid (LPA), lysophosphatidylcholine (LPC) is the major lysophospholipid.

Hydrophobic chains of membrane glycerophospholipids are commonly divided in two subclasses according to whether they are derived from saturated fatty acids (SFAs) characterized by a straight hydrocarbon chain containing most often an even number of carbon atoms or from monounsaturated (MUFA) or polyunsaturated fatty acids (PUFA) containing one or several double bonds, respectively, making the hydrocarbon chain bent (Fig. 1A) [12,13]. The acyl moieties attached to sn-2 of glycerophospholipid's glycerol backbone are commonly unsaturated, unlike the sn-1 moieties that are usually saturated (Fig. 1A) [4]. Aliphatic chains derived from FAs usually contain 12 to 22 carbon atoms [14]. The physicochemical properties of FAs and FAs-derived lipids depend on both the chain length and the saturation level of the acyl chains. UFAs exhibiting a cis-configuration, as referred in this review, have lower melting points than SFAs of the same length [15]. 


\subsubsection{Sphingolipids and sterols}

Besides glycerophospholipids, another structural lipid class is represented by sphingolipids. Ceramide contains a long-chain sphingosine base amide-linked to a saturated or trans-unsaturated FA chain (Fig. 1C). This backbone can be linked with phosphocholine or phosphoethanolamine to give rise to sphingomyelin, or with saccharides in the case of glycosphingolipids. Shingomyelin (SM), due to its narrow cylinder shape, increases the packing density in the membrane $[6,16]$.

In mammals, sterols are represented by cholesterol. The structure of sterols consists in four fused rings forming the steroid nucleus: three rings containing six carbons and one ring with five carbons. Cholesterol is composed of the steroid nucleus, a polar hydroxyl group and a hydrocarbon tail (Fig. 1D) [4]. Cholesterol creates a condensing effect, increasing membrane thickness and impermeability to solutes by interfering with neighboring unsaturated acyl chains and by immobilizing them and reducing their flexibility. Besides, due to its inflexible core formed by the steroid nucleus, cholesterol interferes with acyl chains packing in the membrane. This property allows cholesterol to maintain the membrane fluid in a large temperature range independently of the composition of membrane acyl chains. It is also important in the formation of membrane domains with sphingomyelin due to their property to form 1:1 dimers $[9,17,18]$.

\subsection{Membrane properties}

The membrane lipid composition of each organelle varies according to their specialized tasks. Endoplasmic reticulum (ER) is the organite mediating both the protein folding and lipid synthesis [19]. It is the main site where membrane proteins are inserted [19]. The lipid composition of ER and plasma membranes is definitively different. Adapted to its barrier function, the plasma membrane is thick and tightly packed with a negative cytoplasmic surface charge, unlike the ER membrane that is composed of a thin lipid bilayer with loose packing and a neutral cytoplasmic charge [9]. Their specificity is also governed by differences in the length and shape of transmembrane domains (TMDs) of their proteins. PtdCho, PtdEtn, SM, PtdIns, and PtdSer approximatively represent $43 \%, 21 \%, 23 \%, 7 \%$ and $4 \%$ of the rat liver plasma membrane phospholipids, respectively, with a cholesterol/phospholipid ratio of $0,76[6]$. The concentration in saturated lipid species, beside sterols and sphingolipids $(10-20 \%$ and $5-10 \%$ of total lipids, respectively) is high in the plasma membrane making it rigid and thick to protect cells from external aggressions. However, the PtdCho, PtdEtn, SM, PtdIns, and PtdSer approximatively represent 57\%, 21\%, 4\%, 9\% and $4 \%$ of rat liver ER membrane phospholipids, respectively, with a very low cholesterol/phospholipid ratio of 0,07 [6]. Sterols and sphingolipids are low in the ER while this organelle is the primary site of their biosynthesis. ER supplies ceramide to trans-Golgi to form sphingolipids $[9,20,21]$. Actually, the transition from the thin and loose ER/cis-Golgi membranes into the thick plasma membrane occurs in the trans-Golgi due to its sphingolipid production and sterol supply [22]. Golgi is therefore divided into two distinct parts, cis-Golgi and trans-Golgi, each characterized by a specific membrane composition and organization.

Mitochondria possess bacterial lipids and around $45 \%$ of its phospholipids are autonomously synthesized by the organelle. Phosphatidic acid (PA) and phosphatidylglycerol (PtdGro) are synthesized by mitochondria and used as building blocks for an unique mitochondrial lipid called cardiolipin (CL) (2-5\% of total lipids) [6,23]. As PtdEtn, mitochondrial CL also acquires a preference for non-bilayer configuration [21]. Moreover the mitochondria decarboxylate the PtdSer to produce PtdEtn. PtdEtn is thus particularly enriched in inner membranes of mitochondria (35-40\% of total phospholipids) [6]. In general, the sterol content is low, except for specialized cells in steroid hormone synthesis [24].

Lipid droplets (LD) are the lipid storage organelle found in all living organisms. Besides the neutral lipids triacylglycerol (TG) and diacylglycerol (DG), the LD core can also contain sterol esters and depending on the cell type, retinyl esters, waxes and ether lipids $[25,26]$. The composition of the LD phospholipid monolayer depends on the cell type, but mainly consists of PtdCho, PtdEtn, and to a lesser extent, PtdIns and lysophospholipids.

\subsubsection{Membrane fluidity}

Fluidity is defined as "the quality of a substance of being not solid and able to flow" [27]. According to the fluid mosaic model, a biological membrane is a two-dimensional fluid allowing lipids and proteins to diffuse freely in the plane of the membrane [1]. The current model also takes into account protein complexes, protein-lipid and lipid-lipid interactions. The "fluid" character of a membrane depends on its composition. A disordered, fluid state is imparted by the presence of unsaturated acyl chains that act to offset the closely packed, ordered arrangement of the straight, saturated acyl chains. Multiple possible phase states co-exist in the plasma membrane due to its varied lipid composition. The packed ordered phase enriched in saturated lipids is called the liquid-ordered $\left(L_{o}\right)$ phase. The fluid and disordered phase is mainly composed of unsaturated lipids with a kinked shape and is called the liquid-disordered $\left(L_{d}\right)$ phase $[28,29]$. The presence of cholesterol restricts the movement of surrounding acyl chains but maintains fluidity of the bilayer, inducing a so-called liquid-ordered phase. Long saturated hydrocarbon chains like in SM-rich mixture of lipids adopt a solid-like phase $\left(\mathrm{S}_{\mathrm{o}}\right)$. Both acyl chain length and saturation level affect the membrane phase. However, in most biological membranes composed of glycerophospholipids with unsaturated hydrocarbon chains, liquid-phases are predominant. In fact, artificial mixtures of lipids containing di-saturated PtdCho, di-unsaturated PtdCho and cholesterol are completely miscible like a liquid disordered lipid bilayer at physiological temperature. This miscibility is allowed by the unsaturated hydrocarbon chains of glycerophospholipids and defines the fluid state of biological membranes with a coexistence of $L_{o}$ and $L_{d}$ phases $[23,30]$.

Membrane fluidity can be described and measured by diverse spectroscopic methods, but less demanding techniques, such as microscopy with fluorescent probes, are more frequently used. Designed and synthesized by Gregorio Weber, the Laurdan is a polarity-sensitive fluorescent probe [31]. When inserted into lipid membrane, Laurdan distributes equally between the $\mathrm{L}_{o}$ and $\mathrm{L}_{\mathrm{d}}$ phases but shows a phasedependent emission spectrum. This property gives it a great advantage over other probes that show a non homogenous partitionning in membranes and are insensitive to lipid phase states (such as 1,6-diphenyl-1,3,5-hexatriene, pyrene and parinaric acid). More the lipids are tightly packed in ordered phases, more water is efficiently excluded and more the fluorescence spectrum of Laurdan shifts from the green $(490 \mathrm{~nm})$ to the blue $(440 \mathrm{~nm})[32-34]$.

\subsubsection{Membrane rafts}

In 2006, a Keystone symposium gave rise to a consensus definition of the membrane rafts: "Membrane rafts are small $(10-200 \mathrm{~nm})$, heterogeneous, highly dynamic, sterol- and sphingolipid-enriched domains that compartmentalize cellular processes". Small rafts can sometimes be stabilized to form larger platforms through protein-protein and proteinlipid interactions [35]. The preferential interaction between sphingolipids and cholesterol through strong hydrogen bonds is the principal characteristic of these ordered lipid domains [36]. Saturated glycerophospholipids are also major components of these domains besides ganglioside lipids, a class of glycosphingolipids capable of interacting with cholesterol enriched domains [37]. Post-translationally modified cell surface proteins that carry either the glycosylphosphatidylinositol (GPI) moiety as a membrane anchor or palmitoyl moieties usually favor the lipid raft formation [38]. These lipid-anchored proteins are believed to regulate membrane structure and function. Proteins incorporated into these ordered domains seem to represent $35 \%$ of all plasma membrane proteins but only one-third among them are GPI-anchored or palmitoylated [39]. The proteins embedded in such thicker and more 
ordered domains of the plasma membrane are characterized by longer transmembrane domains [40]. Cortical actin cytoskeleton influences the membrane organization and stabilizes membrane rafts through its direct or indirect coupling with charged and saturated acyl-chain-containing lipid species such as PtdSer [41,42]. In presence of cholesterol, this phenomenon orchestrates the immobilization of inner leaflet PtdSer that are engaged in transbilayer interactions with long acyl chain-containing GPI-anchored proteins located in the outer leaflet. All these interactions between lipids and proteins lead to the formation of locally ordered transbilayer domains $[41,42]$.

Membrane rafts compartmentalize cellular signaling in the plasma membrane. In fact, these domains facilitate the concentration of certain proteins in one specific region of the plasma membrane according to their affinity for rafts components. Moreover, rafts composition can affect protein conformation and thereby regulate protein activity $[43,44]$. Immunoreceptors like high affinity IgE receptor, T cell receptor (TCR) and B cell receptor (BCR) translocate to membrane rafts following their activation $[45,46]$.

\section{Lipid synthesis and remodeling}

\subsection{De novo lipogenesis}

De novo FA synthesis or de novo lipogenesis (DNL) is the metabolic pathway that transforms excess of carbohydrate in FAs (Fig. 2) [47]. FAs are composed of a hydrocarbon chain with a methyl group at one end of the molecule (designated $\omega$ end) and a carboxyl group at the other end. The letter " $\omega$ " is often used to describe the position of the double bond closest to the methyl end. Another systematic nomenclature for fatty acids may also indicate the location of double bonds with reference to the carboxyl group $(\Delta)$ [15]. FAs can also be designated as $\mathrm{X}: \mathrm{Y}$, where $\mathrm{X}$ is the number of carbon atoms and $\mathrm{Y}$ the number of double bonds (e.g. C16:0 for palmitic acid and C18:1 for oleic acid) [15].

In normal conditions, DNL mainly takes place in adipose tissue and liver even if adipose tissue is less responsive to acute or prolonged carbohydrate overfeeding [48]. Fatty acid synthesis occurs in the cytosol (Fig. 2). A citrate molecule, issued from the tricarboxylic acid cycle (TCA) in mitochondria, is hydrolyzed by the "Adenosine

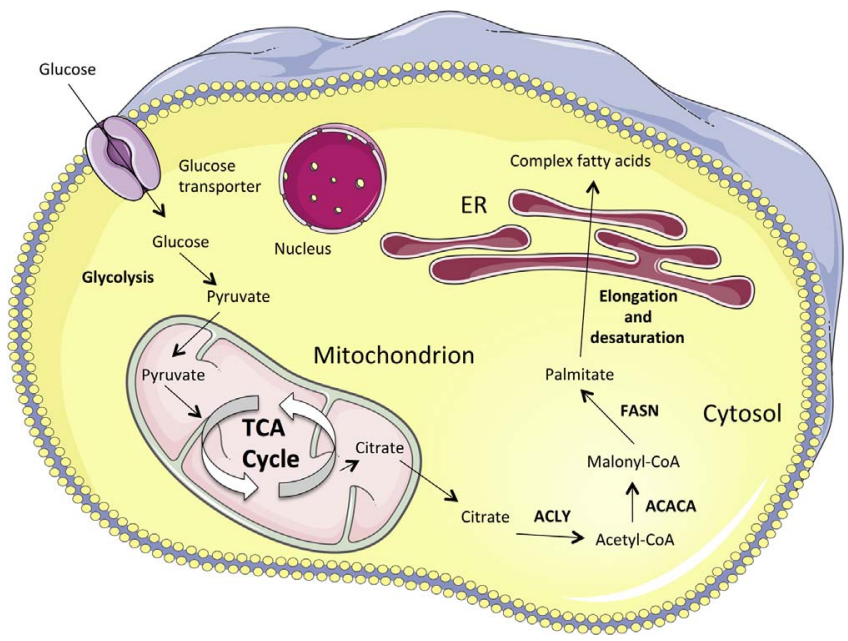

Fig. 2. De novo lipogenesis is a coordinate serie of enzymatic reactions that use the carbons from glucose to generate FAs. The glycolytic pathway generates pyruvate from glucose. In the mitochondrion, pyruvate feeds the tricarboxylic acid (TCA) cycle. A TCA intermediate, the citrate, can be translocated into the cytosol and converted into acetylCoA by ATP-citrate lyase (ACYL). Acetyl-CoA is further carboxylated to malonyl-CoA by acety-CoA carboxylase (ACACA). The multi-enzymatic complex, commonly called «fatty acid synthase» (FASN) processes an acetyl-CoA and several malonyl-CoA to generate a fatty acid, commonly the palmitate, a 16-carbon saturated fatty acid. This could be elongated and de-saturated into complex fatty acids by ER enzymes. triphosphate (ATP) citrate lyase" (ACLY), which generates an acetylCoA. This one is then converted into malonyl-CoA by the "acetyl-CoA carboxylase" (ACACA or ACC). The multi-enzymatic complex, commonly called "fatty acid synthase" (FASN), processes an acetyl-CoA and several malonyl-CoA to generate the palmitate (C16:0), the main product of DNL beside stearate (C18:0) and shorter fatty acids [47]. The glycolytic pathway supplies a carbon source for FA synthesis [49,50]. The expression of genes involved in de novo fatty acid synthesis is tightly regulated by both the transcription factors ChREBP (carbohydrate responsive element-binding protein) and SREBP (sterol regulatory element-binding protein), whose activity is respectively induced by glucose and lipid metabolism intermediates [47,50-52].

\subsection{FA elongation and desaturation}

The ER contains enzymatic machinery allowing the addition of two extra carbon units and of a double bond in the fatty acyl chain (Fig. 2). FA elongation process is a repetition of the FA elongation cycle whereby two carbons are added to the carboxyl end. This cycle consists in four sequential reactions: condensation, reduction, dehydration and another reduction [53]. The first rate-limiting reaction is catalyzed by enzymes that belong to ELOVL family (Elongation of very-long-chain fatty acids) composed of seven isotypes (ELOVL1-7) [53,54]. The introduction of cis-unsaturation at specific locations in the acyl chain is achieved by two distinct enzyme families referred as stearoyl-CoA desaturases (SCD1 and SCD2) and fatty acid desaturases (FADS1 and FADS2). Desaturases influence key biological reactions and mammalian cells only express $\Delta 9$-, $\Delta 6$ - and $\Delta 5$-desaturase activities. Accordingly, long-chain fatty acids of the $\omega 6$ and $\omega 3$ series have to be synthesized from precursors obtained from diet [53].

\subsection{Lipid homeostasis: the SREBP pathway}

Newly synthesized FAs will serve for energy storage when incorporated in TGs or will be used for membrane phospholipid synthesis. However, overproduction of lipids can be deleterious for the cell and toxic for the whole living organism, suggesting that regulatory mechanisms controlling cellular lipid levels are mandatory for cell survival and proliferation [55]. These are mediated by a family of ER membrane-bound transcription factors called sterol regulatory elementbinding proteins (SREBPs) [56]. SREBPs can sense cellular levels of FAs or sterols and modulate transcription of genes coding for lipogenic enzymes. The full length SREBP is sequestered in the ER membrane through its interaction with the SREBP cleavage-activation protein (SCAP) and the insulin-induced gene protein-1 (Insig-1) [57]. When cellular levels of FAs or sterols are low, the SREBP/SCAP complex dissociates from Insig-1 and is transported to the Golgi. SREBP is then processed successively by Site- 1 and Site-2 Proteases (S1P and S2P). Once released, the $\mathrm{NH}_{2}$-terminal bHLH-Zip domain of SREBPs translocates to the nucleus $[58,59]$ where it binds enhancer sequences located in the promoter of genes controlling lipid synthesis, called sterol response elements (SREs) $[55,60]$.

Three isoforms of SREBPs are produced in mammals: SREBP-1a, SREBP-1c and SREBP-2 [61]. SREBP1a and SREBP1-c are produced by alternate promoters from a single gene and are more active in driving transcription of FA biosynthesis genes. SREBP-2 is produced by another gene and is more active in controlling transcription of genes regulating cholesterol production $[60,62]$. SREBP1 is subject to feedback inhibition by PUFAs because its transcription mediated by the nuclear liver $\mathrm{X}$ receptors (LXRs) is antagonized by PUFAs [63-65]. In human, the LXR response element is found in the promoter regions of both SREBP-1a and SREBP-1c [66]. Sterols and UFAs, opposite to SFAs, also inhibit SREBP activation but through another mechanism involving the blocking of Insig-1 degradation [67-69]. 


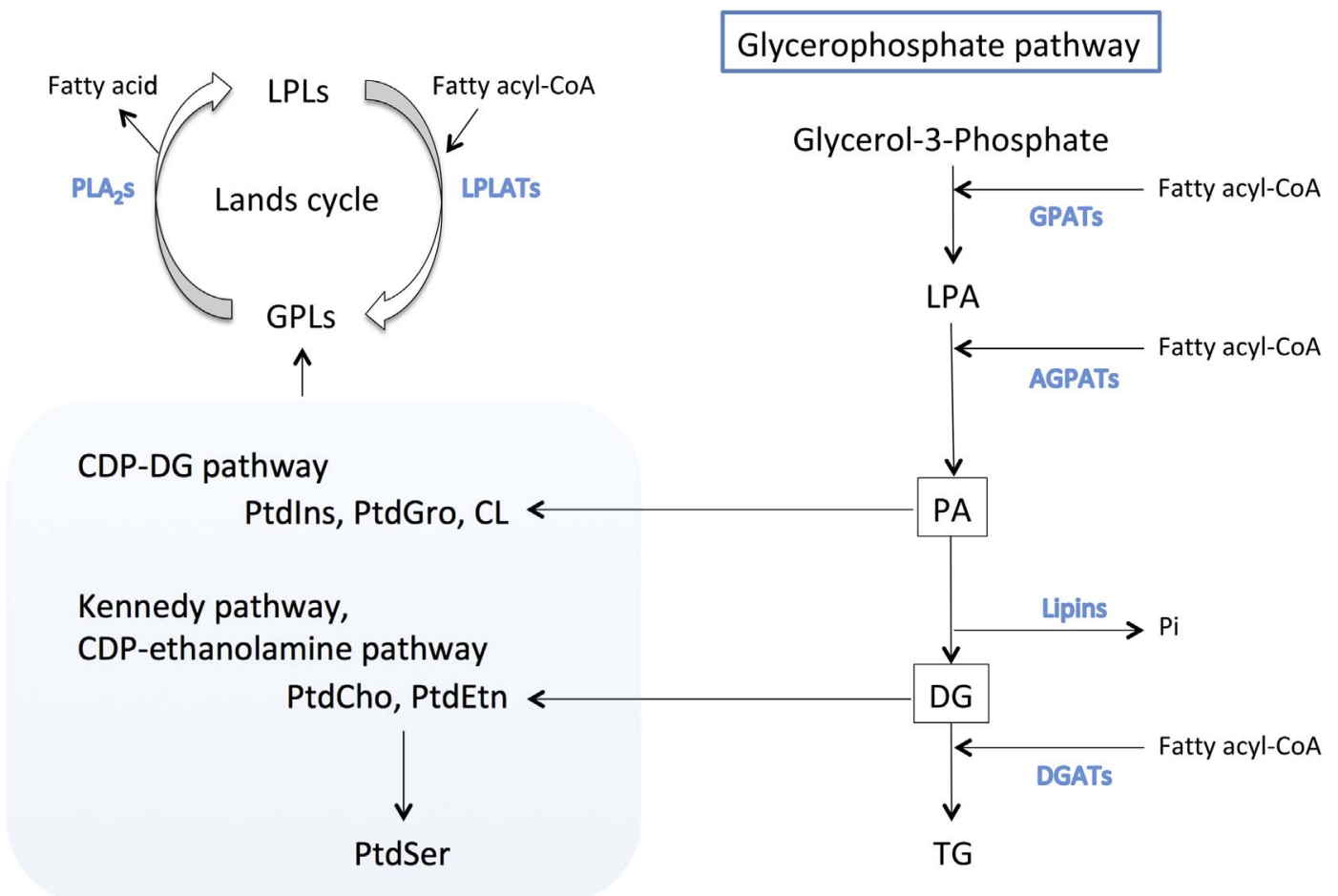

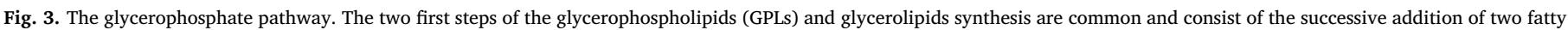

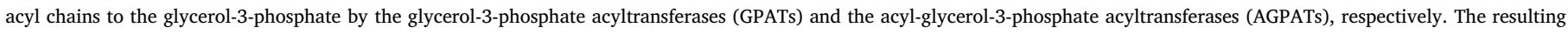

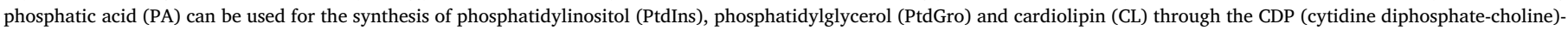

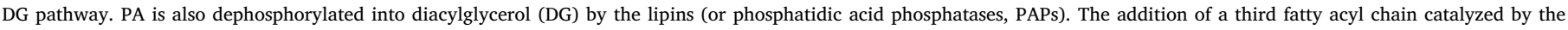

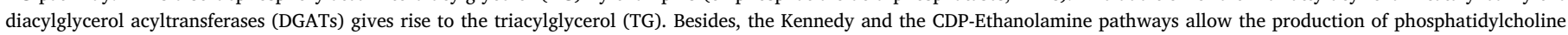

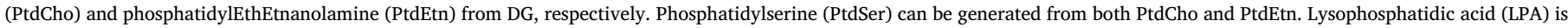

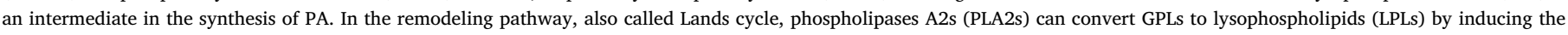
release of the acyl chain from sn-2 position. LPLs can be reacylated by lysophospholipid acyltransferases (LPLATs), giving rise to GPLs with a different acyl chain at sn-2 position.

\subsection{The glycerophosphate pathway}

The synthesis of both glycerolipids (DG and TG) and glycerophospholipids shares common steps and starts from glycerol-3-phosphate. The incorporation of two fatty acyl chains is successively catalyzed by glycerol-3-phosphate acyltransferases (GPATs) and acyl-glycerol-3phosphate acyltransferases (AGPATs) (Fig. 3) [70]. Four GPATs (GPAT1, GPAT2, GPAT3/AGPAT10, and GPAT4/AGPAT6) and at least two AGPATs (AGPAT1 and AGPAT2) are known to be involved in these processes [70]. The specificity of GPATs/AGPATs for fatty acyl-CoA determines the fatty acid composition of the newly synthesized glycero (phospho)lipids [70]. PA is used as an intermediate for the synthesis of glycerophospholipids including the PtdIns, the mitochondrial CL and the PtdGro (Fig. 3) [6]. PA is also dephosphorylated through the lipins (or phosphatidic acid phosphatases, PAP) to form DG that serves as building block for the synthesis of both glycerophospholipids such as the PtdCho, PtdEtn, PtdSer and TG (Fig. 3) [71]. A third round of acylation is needed in order to synthesize TG from DG via the diacylglycerol acyltransferases (DGAT1, DGAT2) (Fig. 3) [72]. In ER, PA serves to build the PtdCho, both the building block of cellular membranes and a potential source of lipid mediators, through the CDP (cytidine diphosphate)-choline pathway also called Kennedy pathway (Fig. 3) [73]. The majority of PtdEtn are synthesized via the CDPethanolamine pathways while PtdIns, PtdGro and CL are synthesized via the CDP-DG pathway (Fig. 3) [6]. An alternative PtdCho synthesis pathway involves the conversion of PtdEtn in PtdCho by three methylation reactions catalyzed by the PtdEtn N-methyltransferase (Pemt). But the only mammalian cell type producing $30 \%$ of their total PtdCho content by this way is hepatocyte [74].

\subsection{Lipid remodeling}

The acyl groups of glycerophospholipids show a high diversity and are not symmetrically distributed. This diversity is not fully explained by the Kennedy pathway. This pathway can explain a highly diverse fatty acid composition generated at the sn-2 position of PA but not of PtdCho, PtdEtn, PtdSer, PtdIns, CL and PtdGro. Saturated and monounsaturated acyl groups are esterified at the sn-1 position, whereas polyunsaturated fatty acyl groups are localized at the sn-2 position of glycerophospholipids [75]. In 1958, Lands described a rapid turnover of the sn-2 fatty acyl groups of glycerophospholipids as a remodeling pathway also called the Lands cycle (Fig. 3) [76]. Besides the generation of membrane glycerophospholipids diversity, this pathway also allows the production of lipid derivatives and lysophospholipids. This cycle is governed by the orchestred activation of phospholipases $\mathrm{A}_{2} \mathrm{~S}$ $\left(\mathrm{PLA}_{2} \mathrm{~s}\right)$ and lysophospholipid acyltransferases (LPLATs) (Fig. 3) [77-79]. To date, LPLATs belong to the 1-acylglycerol-3-phosphate Oacyltransferase (AGPAT) family and to the membrane bound O-acyltransferase (MBOAT) family [79].

\subsubsection{PUFA containing-glycerophospholipids}

The concerted action of PLA $\mathrm{P}_{2} \mathrm{~S}$ and LPLATs is an important source of PUFA-containing glycerophospholipids [78]. Different enzymes with LPC acyltransferase (LPCAT) activity, including LPCAT2 and LPCAT3, are reported to incorporate PUFAs into lysophospholipids. These enzymes have substrate preferences and are expressed differently [80]. For example, LPCAT2 is believed to contribute to the production of lipid mediators in inflammatory cells such as macrophages and neutrophils where it is highly expressed [81]. Besides, the expression of LPCAT3 is ubiquitous, controlled by PPARalpha and liver X nuclear receptors and induced during adipogenesis [82-85]. In HeLa cells, the 
knockdown of LPCAT3 caused reduced incorporation of PUFAs into PtdCho, PtdEtn and PtdSer [86]. Mouse LPCAT3 shows higher acyltransferase activity towards polyunsaturated fatty acyl-CoAs, 20:4-CoA and 18:2-CoA, than towards saturated fatty acyl-CoAs [79,80]. Moreover, induction of LPCAT3 ameliorates SFA-mediated ER stress in vitro, which involves LPCAT3 in the control of inflammation through the remodeling of PtdCho fatty acid composition [87]. Thus, it is obvious that the Lands cycle brings another dimension to the lipogenesis through the production of PUFAs and their incorporation in plasma membranes.

\section{Membrane remodeling and obesity-linked metabolic disorders}

Biological membranes can undergo various kinds of modifications which differentially impact their physico-chemical properties. This remodeling can affect the acyl chains (length, saturation degree) or the head groups of the glycerophospholipids as well as the incorporation of other lipids like sterols and sphingolipids. In general, more the acyl chains are long and saturated, more the phase is liquid-ordered and more the membrane is thick [29]. The cholesterol is able to order unsaturated acyl chains of glycerophospholipids, increasing membrane thickness while maintaining the membrane fluidity [28]. The combinations sphingolipids-cholesterol create membrane domains characterized by an increased membrane thickness and a high lipid packing and order [36]. An increased PtdCho/PtdEtn ratio is often associated to a lower membrane fluidity [88].

It is obvious that these membrane physicochemical properties influence the activity of integral proteins. The transmembrane (TM) part of the protein, often composed of one or several $\alpha$-helices, is poor in polar residues. The length of the hydrophobic core of its TM domain has to match the hydrophobic thickness of the membrane in order not to expose non-polar residues to water. A membrane thickening can induce a conformational modification of the TM domain and thereby can inactivate the protein [89]. The mismatch-induced deformation in the lipid matrix may also induce an indirect, lipid-mediated attraction between two proteins [89]. On the other hand, the lack of freedom mediated by a loss of membrane fluidity can prevent the TM domain conformational transitions required for the catalytic cycle [90]. Besides membrane physicochemical properties, the modifications of the membrane lipid composition can also directly modulate the specific lipidproteins interactions [91].

Several studies have shown that the composition of membrane phospholipids is influenced by the fatty acid composition of the diet [92-94]. A SFA-rich diet will promote a decrease of membrane fluidity. A carbohydrate-rich diet will also have the same trend since glucose is readily converted into SFAs via de novo lipogenesis (DNL) in liver and adipocytes, which can then be distributed throughout the body via lipoproteins or as free fatty acids [95]. Besides diet, an aberrant lipid metabolism can also lead to alterations in membrane lipid composition as seen in some cancer cells [96] or in hepatocytes from obese mice [97].

A so-called "Western diet" rich both in saturated fat and carbohydrates combined with a sedentary lifestyle and genetic risk factors promote energy imbalance and the accumulation of fat depots. Nowadays, it is obvious that obesity strongly increases the risk of developing metabolic disorders like insulin resistance and type 2 diabetes mellitus (T2DM) [98]. FFAs concentrations are actually increased in the plasma and insulin-target tissues of obese patients [99]. A decreased membrane fluidity has been observed in several kinds of cells in patients with T2DM (red blood cells, leucocytes, platelets, cardiac myocytes, ileal enterocytes,...) [100]. Analysis of membrane lipid composition also demonstrated an enrichment of lipid species known to make the membranes less fluid [101-103]. At least two large longitudinal studies demonstrated a correlation between the SFAs levels in red blood cells membranes and the susceptibility to develop T2DM [104,105]. Furthermore, several studies have shown that insulin receptor signaling and GLUT4 transport to the plasma membrane are impaired by a decreased membrane fluidity [106-108]. Altogether, these observations have led researchers to postulate that a loss of membrane fluidity could contribute to the development of obesity-related insulin resistance and T2DM [100].

The following paragraphs describe three other kinds of membrane proteins modulated by membrane lipid alterations, namely the Toll-like receptor 4 (TLR4), the Na, K-ATPase and sarco(endo)-plasmic CaATPase and the ER stress transducer, IRE-1 (inositol requiring enzyme 1). The emphasis is put on both underlying physicochemical mechanisms and relevance in obesity-linked inflammatory and metabolic disorders.

\section{TLR4, the case of an innate immunity receptor modulated by lipid rafts}

The Toll-like receptor (TLR) family in humans comprises 10 pathogen recognition receptors (PRR) [109]. The best studied member, TLR4, has been identified as the receptor of lipopolysaccharide (LPS, endotoxin) anchored in the outer membrane of Gram-negative bacteria. LPS is composed of three parts: the Lipid A, the most conserved part containing several acyl chains and mediating the pro-inflammatory activity, the central oligosaccharidic core and the terminal O-antigen composed of a variable polysaccharidic chain [110]. TLR4 is a transmembrane protein mainly expressed on myeloid cells, containing 22 leucine-rich repeats (LRRs) in its typical horseshoe-shaped extracellular domain, 21 amino-acids in its transmembrane helix (TMH) and about 200 amino-acids for its intracellular part characterized by the presence of the conserved Toll/IL-1 receptor (TIR) domain [111]. TLR4 activation in response to LPS triggers a pro-inflammatory response allowing the eradication of the bacteria [112]. However, abnormal host response to LPS can cause a systemic inflammatory state called sepsis [112]. Furthermore, TLR4 has been shown to play a role in other pathological conditions involving endogenous ligands, notably in obesity-linked insulin resistance and T2DM $[113,114]$.

The usually accepted model of TLR4 activation by LPS is the following one [115] (Fig. 4A). The LPS-binding protein (LBP) in the serum promotes the transfer of LPS monomer to CD14, a myeloid cell specific protein that is GPI-anchored in the outer leaflet of plasma membrane. CD14, in turn, shifts the LPS to the hydrophobic pocket of MD2 in the complex TLR4/MD2. However, one of the acyl chains of the LPS interacts with a neighboring TLR4 molecule allowing the formation of the "M" shaped dimers of the complex TLR4/MD2. This homodimerization triggers the recruitment of adaptor proteins through homotypic TIR-TIR interactions [116]. TIRAP (TIR-containing adaptor protein) and MyD88 (myeloid differentiation factor 88 ) initiate a signaling cascade involving $\mathrm{NF}-\mathrm{KB}$ and the MAP kinases and leading to the production of pro-inflammatory cytokines such as tumor necrosis factor- $\alpha$ (TNF- $\alpha$ ) and interleukin-6 (IL-6) while TRIF (TIR-domain-containing adapter-inducing interferon- $\beta$ ) and TRAM (TRIF-related adaptor molecule), after TLR4 endocytosis, induce the activation of IRF3 (interferon response factor 3) and the expression of type 1 interferons (IFN) and IFN-inducible chemokines, notably IL-10 and RANTES [116].

CD14 plays a key role in TLR4-mediated signaling as demonstrated by studies on transgenic and knockout mice developing a hypersensibility or a resistance to septic shock, respectively [117-119]. This coreceptor not only facilitates the LPS transfer to the complex MD2/TLR4 but also promotes TLR4 internalization $[120,121]$. Since CD14 is a GPIanchored membrane protein, it constitutively accumulates in the outer leaflet of membrane rafts. Studies measuring the fluorescence resonance energy transfer (FRET) between proteins known to be constitutively associated to rafts and other selected proteins demonstrated that LPS could induce a raft-based molecular platform containing CD14, TLR4 and other proteins susceptible to participate both to the LPS recognition and downstream events [122]. Interestingly, analyses of fluorescence recovery after photobleaching (FRAP) showed that the 


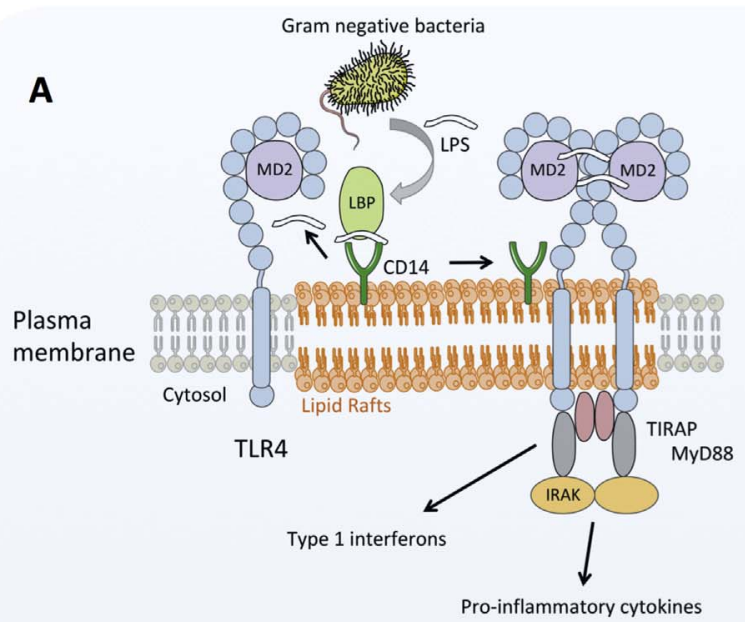

B

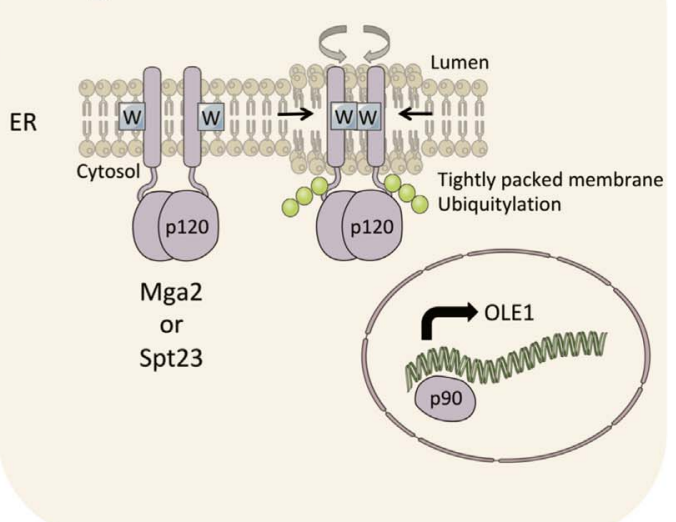

C
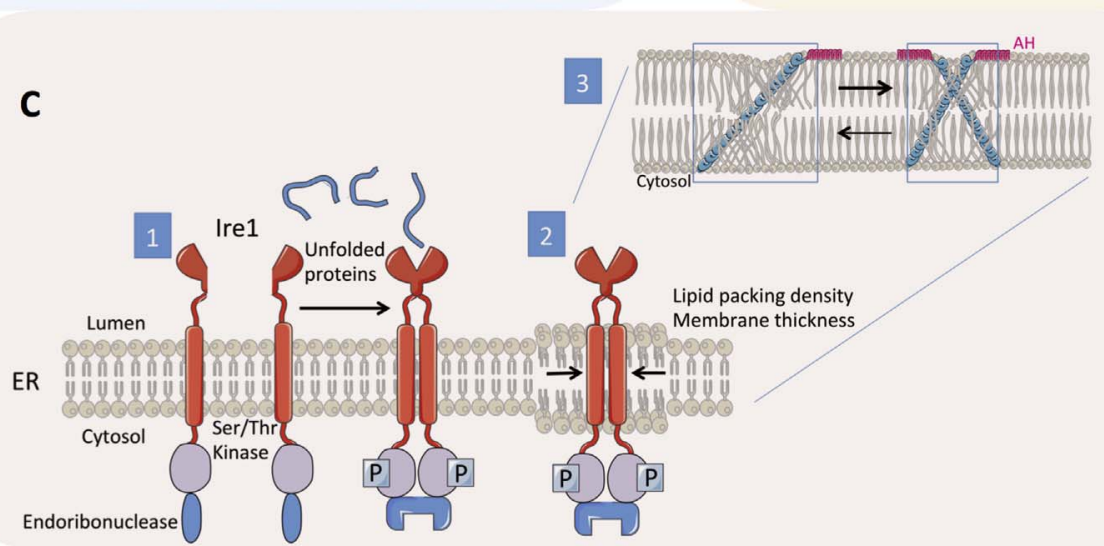

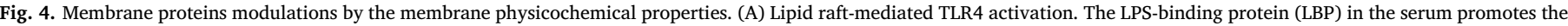

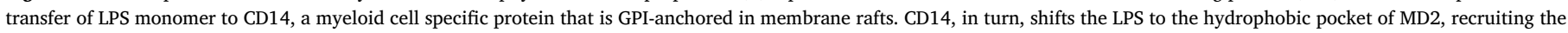

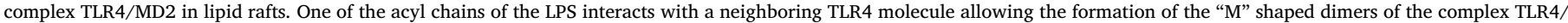

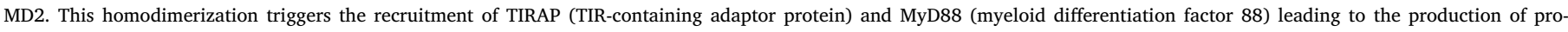

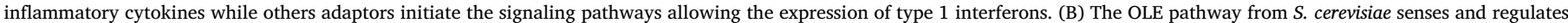

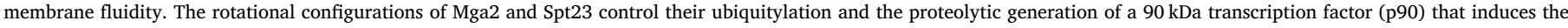

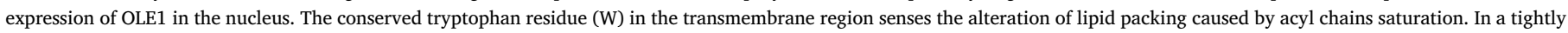

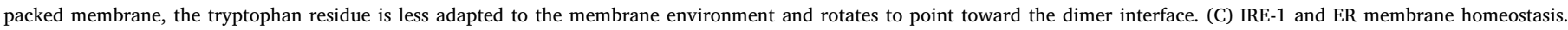

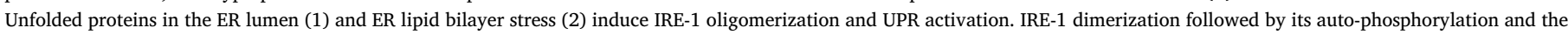

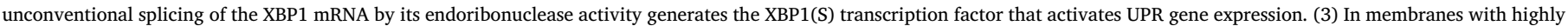

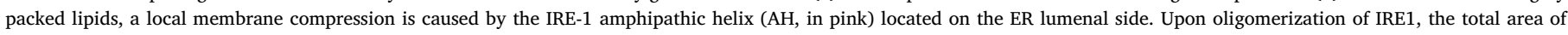
membrane compression (blue rectangles) is reduced.

lateral mobility of TLR4 in the plasma membrane is decreased after LPS stimulation suggesting its sequestration in rafts [123]. Lipid raft integrity is required for LPS signaling as demonstrated by the inhibiting effect of raft-disrupting drugs [122]. Proteomic analyses performed on the detergent-resistant membrane (DRM) fraction of macrophages revealed the LPS-induced recruitment of several proteins such as CD14, CD44, Src family tyrosine kinases, Hsp70, Hsp90, acidic sphingomyelinase,... [124]. Altogether, these data show that TLR4 activation is concomitant to its association with other accessory proteins at the site of CD14-LPS ligation, within the membrane rafts (Fig. 4A) [125].

Since the formation of membrane rafts is mediated by preferential interactions between cholesterol and sphingolipids, it is not surprising that the depletion or enrichment of cholesterol in the plasma membranes prevents or promotes, respectively, the TLR4 clustering with accessory proteins in rafts and the TLR4-dependent pro-inflammatory signaling $[122,123,126,127]$. The first study devoted to the investigation of FFA effects on TLR4 signaling showed that lauric (C14:0), palmitic (C16:0), and stearic (C18:0) acids could induce cyclooxygenase-2 expression through a TLR4-dependent mechanism in a macrophage cell line and this SFA-mediated stimulating effect could be inhibited by PUFA [128]. Later, the same group demonstrated that SFAs could induce the dimerization of TLR4 as well as its recruitment with effector molecules to the DRM fraction [129]. Obviously, the next step was to investigate the mechanism by which SFAs activate TLR4. The hypothesis in favor of a direct interaction between SFAs and the complex TLR4/MD2 was eliminated [130,131]. Instead, an indirect mechanism involving the glycoprotein, fetuin $\mathrm{A}$, was proposed to mediate the binding of SFAs to TLR4. The complex palmitate-fetuin A was shown to stimulate the pro-inflammatory cascade through a TLR4-dependent pathway [132]. Since then, further studies demonstrated that the fetuin-A plays a key role in the mechanisms linking high fat diet and the development of a metabolic inflammation [133]. However, some arguments suggest that even in the absence of fetuin A, SFAs can induce TLR4 dimerization without involving the lipid binding pocket of the complex TLR4/MD2 [134]; first, SFAs concentrations required to induce TLR4 dimerization need to be much higher $(>100 \mu \mathrm{M})$ than those of natural ligands (pM) and secondly, the pre-treatment of macrophages with lauric acid (C14:0) primes LPS-mediated NF- $\mathrm{KB}$ activation, meaning that SFA do not compete with LPS for the binding to the hydrophobic pocket of the complex TLR4/MD2. Interestingly, the same conclusions can be drawn for the SFA-induced dimerization of the TLR2 with TLR1, both receptors that also carry lipid binding pockets for the 
fatty acyl chains of their natural ligand (acylated lipopeptides) [135]. Since phospholipids in lipid rafts are pre-dominantly acylated by saturated fatty acids, these ones were proposed to mediate the homodimerization of TLR4 or hetero-dimerization of TLR2 and TLR1 by promoting the formation of lipid rafts and the TLRs recruitment [134]. This hypothesis is reinforced by the observation that $\omega$-3 PUFA are able both of modifying the lipid composition of lipid rafts and inhibiting LPS- or lauric acid-induced TLR4 dimerization into lipid raft fractions [128,136,137].

In vivo, such dietary compounds like cholesterol, SFAs, MUFAs, $\omega 3$ and $\omega 9$ PUFAs modulate the pro-inflammatory activity of TLR4. Indeed, a diet rich in saturated fat increases susceptibility of mice to sepsis [138] while $\omega 3$ PUFAs have been shown beneficial in protecting humans and rodents against sepsis [139]. On the other hand, obese patients display an exacerbated morbidity from sepsis [140]. In addition to sepsis, TLR4 is known to play a role in the development of obesitylinked inflammation and insulin resistance as demonstrated in TLR4 deficient mice and in subjects with the most common loss-of-function TLR4 polymorphisms [113,114,133]. SFAs whose levels are significantly increased in the plasma and adipose tissue of obese individuals are among the major endogenous triggers of TLR4 in obesity [99]. More recently, changes in the landscape of the gut microbiota related to obesity and commonly associated diseases have been proposed to be at the origin of an increased gut permeability and LPS leakage leading to increased LPS levels in the blood [141-143]. Together, LPS and SFAs could act synergistically and systemically to induce TLR4 dimerization and activation in membrane rafts and to promote inflammation in obesity.

\section{The Na, K-ATPase and sarco(endo)-plasmic Ca-ATPase} regulated by both general and specific lipid-protein interactions.

Discovered 60 years ago, the Na, K-ATPase is currently considered as an essential and ubiquitous membrane transport protein whose primary function is the establishment and maintenance of high $\mathrm{K}^{+}$and low $\mathrm{Na}^{+}$concentrations in the cytoplasm [144]. Such concentrations are important for various enzymatic functions within the cell. Furthermore, energy stored in the ionic gradients across the plasma membrane is used for secondary transport of molecules (neurotransmitters, metabolites,...) and other ions $\left(\mathrm{H}^{+}, \mathrm{Ca}^{2+}, \mathrm{Cl}^{-}\right)$. The ion gradients also enable rapid signaling by opening of sodium or potassium selective channels in the plasma membrane in response to extracellular signals.

Minimal functional unit of the Na, K-ATPase is composed of a large $\alpha$ catalytic subunit and a scaffolding $\beta$ glycoprotein [145]. The Na, KATPase belongs to the P-type ATPase family characterized by the Albers-Post reaction mechanism [146]. This one involves the ATP-dependent cyclic transition of the $\mathrm{Na}$, K-ATPase between two different conformational states, E1 and E2, which binds three $\mathrm{Na}^{+}$and two $\mathrm{K}^{+}$, respectively. Different $\alpha$ isoforms are expressed in a tissue-specific manner [147,148]. The $\alpha 1$ isoform is ubiquitous, the $\alpha 2$ and $\alpha 3$ isoforms are expressed in skeletal muscle, neuronal tissue and cardiac myocytes. The $\alpha 4$ isoform is only expressed in the testis. The various isoforms fulfill specific conditions required by the different cell types to maintain ionic homeostasis. The overall structure of the Na, K-ATPase is composed of ten TMHs important for ion binding and three cytosolic domains, the N-terminal domain mediating ATP binding, the P-domain carrying phosphorylation sites and the A-domain that confers ATP hydrolyzing activity $[149,150]$.

Many organs such as kidneys, brain and testis use the sodium and potassium gradients for their specialized functions [151]. Mutations in the genes of the various $\alpha$ isoforms have severe and often neurological consequences [151].

All $\alpha$ isoforms contain a binding site in their extracellular domain for cardiotonic steroid (CTS) compounds, such as ouabain and digitoxin produced by plants $[152,153]$. The CTS stabilize the Na, K-ATPase in E2 conformation, thereby inhibiting its pump activity [154]. Low levels of endogenous ouabain can be measured in human plasma and were proposed to be produced by the adrenal cortex [152,153]. In cardiac myocytes, CTS induce an increase of intracellular $\mathrm{Na}^{+}$, which leads to the accumulation of intracellular $\mathrm{Ca}^{2+}$ through functional coupling to the $\mathrm{Na}^{+} / \mathrm{Ca}^{2+}$ exchanger (NCX) stimulating contractility [155]. Since CTS concentrations much lower than $\mathrm{Na}$, K-ATPase IC $_{50}$ were recognized a long time ago to stimulate growth-linked pathways, the $\mathrm{Na}$, $\mathrm{K}$-ATPase is suspected to have functions independent on its pump activity [156]. Besides the control of ionic concentrations, it is now wellaccepted that the Na, K-ATPase plays a key role in cellular signal transduction through both direct interactions with signaling proteins and its ability to organize specific membrane microdomains [156].

The Na, K-ATPase pump activity has been known for a long time to be modulated by the physical properties of the lipid bilayer. These studies were based on model systems using reconstitution of the Na, KATPase into liposomes of defined lipid composition. The so-called hydrophobic matching principle proposes that the hydrophobic core of the protein transmembrane (TM) domain has to match the hydrophobic thickness of the membrane to avoid the exposition of non-polar residues to water [157]. The bilayer thickness increases with both the length of phospholipids acyl chains and the percentage of cholesterol. Accordingly, the activity of the Na, K-ATPase reconstituted into liposomes is influenced by the acyl chains length in a way dependent on the percentage of cholesterol $[91,158]$. The optimum was reached for a smaller number of $\mathrm{C}$ atoms when cholesterol was added, reinforcing the hydrophobic matching hypothesis $[91,158]$. However, in liposomes where the bilayer thickness is optimal either with or without cholesterol, the enzymatic activity is strongly boosted by the presence of cholesterol $[91,158]$. From that moment, specific cholesterol-mediated effects were proposed in addition to its general effects on physicochemical properties of biological membranes. Later, this hypothesis was confirmed when specific cholesterol binding sites were resolved in the crystal structure of the Na, K-ATPase $[159,160]$. Thanks to the development of membrane protein crystallization within the last decade, specific interactions of the Na, K-ATPase not only with cholesterol but also with phospholipids were highlighted in three distinct pockets of the TM domain $[91,160]$. Biochemical studies were required to address both the role and precise location of each bound lipid. The effects of phospholipids and cholesterol were determined on the wild type or mutated recombinant $\mathrm{Na}$, K-ATPase purified in mixed detergent-lipid-protein micelles in the absence of a lipid bilayer. These studies indicated that (1) anionic lipids (optimally 18:0/18:1 PtdSer) and cholesterol bind in pocket A and are required to stabilize the Na, K-ATPase [91,161,162] (2) polyunsaturated neutral phospholipids (optimally 18:0/20:4 or 18:0/22:6 PtdCho/PtdEtn) stimulate the Na, K-ATPase activity probably through the pocket B $[91,163,164]$ (3) saturated PtdCho or sphingomyelin + cholesterol inhibit the Na, K-ATPase activity likely through the pocket C, known also to host cholesterol [91,164]. Very recently, the team of Karlish, through native mass spectrometry (MS) and site-directed mutagenesis, identified the PtdSer and PtdCho/PtdEtn specific binding sites and underlying modulation mechanisms: PtdSer (and cholesterol) bind between $\alpha \mathrm{TM} \mathrm{8,} \mathrm{9,} \mathrm{10,} \mathrm{and} \mathrm{maintain} \mathrm{topological}$ integrity of the labile $\mathrm{C}$ terminus of the $\alpha$ subunit (site A) while PtdCho/ PtdEtn bind between $\alpha \mathrm{TM} 2,4,6$, and 9 and accelerate the rate-limiting E1P-E2P conformational transition (site B) [165].

Interestingly, a correlation between a decreased $\mathrm{Na}$, K-ATPase activity and a higher saturation level of membrane phospholipids in erythrocytes has been already demonstrated in hypertension cases $[166,167]$. An alteration of the Na, K-ATPase activity was also observed in insulin-resistant tissues of obese individuals and proposed as a risk factor for cardiovascular diseases [168,169].

The sarco/endoplasmic reticulum (SR/ER) $\mathrm{Ca}^{2+}$ ATPase (SERCA), belonging to the same P-ATPase family, transports calcium ions from the cytoplasm to the SR/ER and plays a key role in $\mathrm{Ca}^{2+}$ homeostasis [170]. Different SERCA isoforms encoded by three different genes are 
differentially expressed according to the species and tissues [170]. The crystal structures of skeletal muscle SERCA1a in phospholipid bilayer have been determined for several conformational states of the reaction cycle [171]. More recently, the entire first layer of phospholipids surrounding the transmembrane helices of $\mathrm{Ca}^{2+}$-ATPase in four different states was resolved [172]. Interestingly, specific protein-phospholipid interactions have been shown to enable the reaction cycle. Two classes of protein residues mediate these interactions: (1) some basic residues (Arg/Lys) snorkel from within the bilayer, exhibiting their positively charged side chain to the negative head groups of specific phospholipidic partners, leading to a local distorsion when the transmembrane helices move to reach the next conformational state while other basic residues can interact through a reversible way with different phospholipids from above to facilitate the conformational switch, (2) Trp residues enable the tilt of the entire protein allowing the large perpendicular movements of the transmembrane helices during the reaction cycle. Surprisingly, the fatty acyl chain properties such as the length or the saturation level do not seem to influence the PtdCho binding to specific sites [173]. However, the impact of these modifications on the pump activity has not been yet investigated. Unlike the $\mathrm{Na}$, K-ATPase, the absence of specific cholesterol binding sites in the SERCA1a crystal structures fits with the very low levels of this sterol in ER membranes [91]. Both closely related Na, K-ATPase and Ca-ATPase seem to have adapted to their own lipid environment. Accordingly, contrary to the Na, K-ATPase, the activity of SERCA1a is not promoted by cholesterol [91]. SERCA1a was even inhibited when reconstituted in synthetic vesicles containing PtdCho/PtdEtn in the presence of cholesterol [174].

Some reports demonstrated that an increase of ER membrane lipid order through cholesterol or saturated PtdCho enrichment could inhibit the ubiquitous isoform SERCA2b probably through the decrease of its conformational freedom [90]. Authors suggested that this cholesterolmediated SERCA2b inhibition would cause the depletion of ER calcium stores, that is an event well-known to trigger ER stress and apoptosis of cholesterol-loaded macrophages in advanced atherosclerotic lesions [90].

The SERCA inhibition in response to a ER membrane remodeling was also observed in liver of obese mice [97]. The comparison of both the proteome and lipidome of hepatic ER between obese and lean mice revealed an increase in de novo lipogenesis and an alteration in ER lipid composition. ER lipids were enriched with SFA and MUFA at the expense of PUFA. In addition, the PtdCho/PtdEtn ratio was increased from 1.3 in lean mice to 1.97 in obese mice, probably because of the upregulation of two key genes involved in PtdCho synthesis and PtdEtn to PtdCho conversion (Choline-phosphate cytidylyltransferase A, Pcyt1a and Pemt) [97]. The calcium transport activity of microsomes prepared from livers from these obese mice was impaired compared to lean mice while the SERCA2b protein level was even slightly higher [97]. The expression of a short hairpin RNA (shRNA) targeting Pemt through an adenoviral vector in the liver of obese mice succeeded in restoring both the normal PtdCho/PtdEtn ratio and calcium transport activity, suggesting that a too high PtdCho/PtdEtn ratio in ER membrane is an event inhibiting SERCA activity in the liver of obese mice [97]. Interestingly, all hepatic ER stress markers were also corrected after Pemt suppression in obese livers, highlighting once again the key role of SERCA in ER homeostasis. A significant reduction in hepatic steatosis and in both hyperglycaemia and hyperinsulinaemia in obese mice was also observed after the suppression of hepatic Pemt expression [97].

\section{Homeoviscous adaptation}

Poikilothermic organisms that do not control their body temperature such as bacteria, cyanobacteria, fungi, plants, and fish increase the proportion of unsaturated acyl chains in membrane lipids to maintain fluidity in the cold [175-177]. This mechanism called homeoviscous adaptation allows the poikilothermic organisms to preserve the membrane fluidity and function over a broad range of temperature [178-180]. This adaptation is not exclusively focused on lipid acyl chains. For example, the lipidome of $S$. cerevisiae cultured at different temperatures shows significant differences in sterol content besides glycerophospholipids and sphingolipids modifications [181,182]. In this section, we will briefly describe the membrane fluidity sensing mechanisms in bacteria, yeast and nematode that have been deeply reviewed previously before addressing such systems in mammals [177-180,183].

The sensing of membrane fluidity in B. subtilis is mediated by DesK, a membrane dimeric protein with five transmembrane helices (TMH) and a cytosolic kinase/phosphatase domain [177]. The membrane thickening during cooling or saturation of lipid acyl chains is sensed by DesK that switches from a phosphatase- to a kinase-active state. In these conditions, Desk autophosphorylates and phosphorylates the transcriptional regulator DesR that, in turn, allows the expression of the des gene encoding for $\Delta 5$-desaturase $[179,184,185]$. The $\Delta 5$-desaturase catalyzes the introduction of a cis-double bond at the $\Delta 5$-position of a wide range of SFAs [186-188]. The incorporation of newly synthetized UFAs in membrane phospholipids allows to restore membrane fluidity. The recovery of initial membrane thickness favors the phosphataseactive state of DesK that turns off des transcription through the dephosphorylation of DesR [179].

In eukaryotes, the situation becomes more complicated. Indeed, they are endowed with different organelles with a specific membrane composition and function. As described above, the plasma membrane is thicker than ER and Golgi membranes [189]. Due to this great diversity in membrane biophysical properties, eukaryotic cells had to establish another membrane surveillance mechanism that does not rely on the sensing of membrane thickness. Such mechanism was described in $S$. cerevisiae that developed a pathway able to sense fluctuations in ERmembrane lipid packing and to lead to the expression of the single and essential $\Delta$ 9-FA desaturase, Ole1, hence the name "OLE pathway" [178] (Fig. 4B). Two homodimeric transcription factors, Mga2 and Spt23, embedded in ER membrane via a C-terminal TMH control the expression of OLE1 [176]. The sensor mechanism of dimeric Mga2 involves rotational motions of its TMH. Interestingly, a conserved tryptophan residue seems to mediate the sensing of lipid packing; this residue can point its bulky lateral chain towards a loosely packed lipid bilayer but when the membrane environment becomes more densely packed, it has to "hide" inside the dimer then promoting the TMH rotational motion (Fig. 4B) [190]. This conformational change makes ubiquitylation sites accessible on the cytosolic side. The E3 ubiquitin ligase Rsp5 recognizes these membrane-bound precursors of $120 \mathrm{kDa}$. Once ubiquitinated and processed by the proteasome, active transcription factors of $90 \mathrm{kDa}$ are released to induce the expression of OLE1 in the nucleus [191]. It is likely that the activation of Spt23 occurs via a similar mechanism due to the high sequence similarity between Mga2 and Spt23 in the sensory TMH region (86\% sequence identity) [183,190].

Finally, a sensing mechanism of the plasma membrane fluidity was also identified in the nematode $C$. elegans and consists of at least two proteins, PAQR-2 and IGLR2. C. elegans mutants lacking PAQR-2 or IGLR-2 have identical phenotypes including cold sensitivity, an excess of SFAs in membranes and a reduced expression of $\Delta 9$-desaturase fat-7 [192]. Moreover, both mutants are glucose intolerant, exhibiting a strong increase in the proportion of SFAs in phospholipids and a concomitant lethal loss of membrane fluidity when they are cultivated in the presence of glucose [192]. The glucose intolerance in the paqr-2 or iglr-2 mutants can be overcome by mutations that cause increased FA desaturation or by treatment with mild detergents, confirming that glucose cytotoxicity results from an altered membrane fluidity [192]. In the model proposed by the authors, the formation of the complex PAQR-2/IGLR2 in plasma membrane could be facilitated by the loss of membrane fluidity, leading to activation of effectors that promote fatty acid turnover and desaturation. Such effectors are still unknown while 
SBP-1 and NHR-49, both C. elegans homologs of the mammalian SREBP and Hepatocyte Nuclear Factor 4 (HNF4)/ Peroxisome proliferator-activated receptor alpha (PPAR $\alpha$ ), respectively, have been proposed to fulfill this function [192-195]. Interestingly, PAQR-2 is the worm homolog of the human adipokine receptors, AdipoR1 and AdipoR2 [196-198]. In light of these data and since the adiponectin exerts a well-known diabetes-preventing effect, it is tempting to postulate that such anti-diabetic effect could be partially mediated through the control of membrane homeostasis.

\section{IRE-1 senses ER lipid bilayer stress through its unusual amphipathic helix}

ER plays a key role in cell homeostasis, mediating both protein folding and lipid synthesis. When ER is overwhelmed, misfolded proteins accumulate in ER membrane and lumen, creating an ER stress. The protein folding homeostasis is restored through an adaptative mechanism called "unfolded protein response" (UPR) that allows both to slow translation and upregulate chaperone expression and ER-associated degradation machinery (ERAD). In higher eukaryotes, the UPR is mediated by three main branches, each one characterized by an ER membrane transducer sensing misfolded proteins in lumen: IRE-1 (inositol requiring enzyme 1), PERK (double-stranded RNA-activated protein kinase [PKR]-like ER kinase), and ATF6 (activating transcription factor 6) [199-202].

IRE-1 is the most conserved sensor of ER stress. It is comprised of a single transmembrane helix (TMH), an N-terminal ER-lumenal sensor domain and a C-terminal cytosolic effector domain with serine/threonine kinase and endoribonuclease activities (Fig. 4C). Upon the binding of unfolded proteins and the dissociation of the chaperone BiP, IRE-1 homodimerizes and goes through trans-autophosphorylation which promotes the activation of its endoribonuclease (RNase) activity. Its RNase activity induces the splicing of XBP1 (X-box binding protein-1) mRNA. The XBP1(S) protein translocates to the nucleus where it binds to UPR elements (UPREs) that regulate the expression of ERAD elements, chaperones and genes involved in lipid synthesis [202-204].

The branch IRE-1/XBP1 is a well-characterized lipid synthesis regulating pathway. Forced XBP1(S) expression increases ER size due to membrane expansion, concomitant with PtdCho and PtdEtn biosynthesis and increased expression of lipid synthesis genes [205-207]. Besides, genetic deletion of $X b p 1$ gene reduces ER size [208]. The increase of ER volume is an important mechanism for resolving ER dysfunction because it helps to rescue luminal protein misfolding independently on chaperones [209]. Accordingly, misfolded proteins-activated UPR controls cellular lipid levels and ER size.

Interestingly, it has become obvious that UPR sensors are also highly influenced by the properties of the surrounding membranes. In absence of ER-lumenal domain required for the binding of unfolded proteins, IRE-1 and PERK are activated by an aberrant membrane environment such as excess of saturated lipids [210]. Moreover, IRE-1 can sense diverse abnormalities in ER membrane caused, for example, by inositol depletion, impaired PtdCho biosynthesis, disrupted sterol homeostasis and sphingolipid production, as well as by increased levels of saturated lipids [39,210-215]. It was shown that TMH is essential for the membrane sensing properties of IRE- $1 \alpha$ and PERK but underlying mechanisms have remained elusive for a long time [210].

However, Halbleib et al. could recently decipher the molecular mechanism of lipid bilayer stress-mediated IRE-1 activation [203]. Their attention was drawn by the unusual and conserved architecture of IRE-1 TMH; an amphipathic helix (AH) is adjacent to the TMH on the ER-lumenal side (Fig. 4C). Using knock-in yeast strains expressing Ire1 wt or Ire1 carrying mutations disrupting the amphipathic character of its $\mathrm{AH}$, authors could demonstrate that this unusual structure was required for Ire1 functionality [203]. The TMH region containing the intact or mutated juxta-membrane $\mathrm{AH}$ was reconstituted in different kinds of liposomes; more the lipid packing was dense, more oligomerization of the wild type peptide was stimulated while the mutated peptide did not oligomerize whatever the level of lipid packing. Altogether, these data suggest that Ire1 uses its AH to sense lipid bilayer stress. Molecular dynamic (MD) simulations of the wt or mutated sensor peptide allowed them to propose a model for the membrane-based Ire1 activation mechanism (Fig. 4C). AH with both its hydrophilic part facing the aqueous environment and its hydrophobic part entering the lipid bilayer forces the TMH into a highly tilted position inside the membrane (Fig. 4C). Accordingly, wt sensor peptide induces a local membrane compression and a disordering of the lipid acyl chains which are more pronounced in a more ordered and thicker membrane environment. In this case, Ire1 oligomerization is energetically more favorable. The mutation inducing a loss of the amphipathic character prevents the corresponding residues to insert into the lipid bilayer and to exert a membrane compression [203]. Interestingly, this sensory mechanism radically differs from the rotational motions of the Mga2 THM that control the production of unsaturated lipids via the OLE pathway.

Therefore, besides the initially known property of UPR in maintaining ER protein homeostasis, the UPR senses and resolves ER lipid bilayer aberrancies. IRE-1 orchestrates therefore lipid membrane and protein folding homeostasis providing new comprehensive mechanisms of the UPR activation and control via interdependent and combined ways.

Interestingly, both modulations in the ER lipid composition and UPR activation are observed in morbid obesity [216,217]. Furthermore, ER stress deeply linked to mitochondrial dysfunction and ROS (reactive oxygen species) production has been involved in the development of insulin resistance or beta-cell death in morbid obesity [218-222].

\section{Conclusions}

A growing number of data indicate that the disruption of membrane homeostasis can be an event triggering signaling cascades through both the modulation of membrane receptors, transporters, ionic pumps, channels or the activation of membrane surveillance systems. Such membrane remodeling can occur in response to an aberrant metabolism as seen in obesity. We have addressed these issues by focusing on the TLR4, the Na, K-ATPase and SERCA and finally the ER stress sensor, IRE-1 in order to illustrate different modes of membrane sensing that are relevant in the context of obesity. Obviously, several other membrane receptor systems such as growth regulatory (epithelial growth factor receptor, EGFR), neurological (serotonin, acetyl choline, opioid receptors), immunological (CD40 receptor and T-cell receptor) and rhodopsin-like $\mathrm{G}$ protein-coupled receptors are also modulated by membrane lipids and are the focus of other comprehensive reviews $[45,223,224]$.

The impact of a membrane remodeling on TLR4 function stems from the fact that its activation requires its translocation in the plane of plasma membrane, leading to its association with CD14 and its homodimerization in membrane rafts [122-125]. The involvement of lipid rafts in the TLR4 activation mechanism partially accounts for its role in obesity-linked inflammation [139]. This kind of raft-based molecular platform is not without precedent in immune pathways since it has been also described upon activation of immunoreceptors like the TCR and BCR [45].

The Na, K-ATPase exemplifies a new concept according to which direct interactions between specific residues and particular lipids determine both stability and activity of the pump in parallel with indirect effects of the lipid bilayer [91]. The closely related SERCA embedded in the more fluid ER membrane seems to be more sensitive to a lipid bilayer stress like demonstrated by its inactivation in cholesterol-loaded macrophages [90] or its inhibition mediated by an increased PtdCho/ PtdEtn ratio in obese mice hepatocytes [97].

Very recently, an IRE-1-mediated mechanism able to sense ER lipid bilayer stress and to restore ER membrane homeostasis was proposed in 
mammals [203]. Interestingly, an unusual amphipathic helix conserved among IRE-1 proteins is embedded in the luminal face of the ER membrane, adjacent to the transmembrane domain and causes a local membrane compression. The model of IRE-1 activation suggests that the total area of membrane compression in a more ordered and thicker membrane is minimized upon oligomerization of IRE-1. Accordingly, IRE-1 is also capable to detect defects in the lipid composition of ER membranes, just as it does detect protein folding dysfunctions within the ER lumen and it solves both the problems at least partially by stimulating lipid synthesis.

Growing evidence indicates that abnormal lipid synthesis is itself the primary driver of liver ER dysfunction in some human metabolic and obesity-related pathologies $[225,226]$. The recent data concerning IRE-1 definitively establish a link between its activation and the lipid bilayer stress and allow to better understand the exacerbating role of ER membrane remodeling in such metabolic diseases. Hepatocytes upregulate TG synthesis in response to nutrients. The TG synthesis pathway overlaps with that of membrane glycerophospholipids. Under conditions of excess TG production like in obesity, the synthesis of membrane glycerophospholipids is also upregulated producing an alteration in the saturation profile and in the ratio PtdCho/PtdEtn of ER membrane phospholipids [97,227]. These perturbations in ER membrane lipid composition not only induce a dysfunction of the SERCA calcium pump followed by a protein misfolding due to impaired function of calciumdependent chaperones but are also directly sensed by IRE- 1 creating a vicious cycle by further increasing lipid synthesis and ER dysfunction $[97,227]$. Since the liver plays a central role in the control of circulating lipids, this hepatic ER disorder contributes to the development of systemic metabolic defects such as hyperglycemia and insulin resistance.

The NLRP3 inflammasome activation is another cellular event both associated to membrane remodeling and relevant in obesity-linked metabolic disorders. This molecular complex mediates the processing of the Pro-IL- $1 \beta$ into mature IL- $1 \beta$ and is activated in response to many danger-associated molecular patterns (DAMPs) [228]. It is well-known to instigate the obesity-linked inflammation and insulin resistance [229]. We demonstrated its activation in SFAs-treated human macrophages as well as in visceral adipose tissue macrophages of metabolically unhealthy obese [230-233]. Interestingly, SFA-mediated NLRP3 inflammasome activation was recently shown to be associated to an accumulation of saturated PtdCho in macrophages membranes [234]. The sensing mechanism is still under investigation.

In light of these recent data, the previous "membrane-centric view of T2DM" comes back to the point and opens novel experimental and therapeutic avenues [100]. Due to the new sophisticated techniques allowing to study the lipidome and the biophysical properties of biological membranes, new mechanisms able to sense and restore the specific membrane lipid composition of other organelles such as mitochondria will be probably discovered in the next future.

\section{Acknowledgments}

This work was supported by the belgian F.R.S.-FNRS and the Leon Fredericq fondation from ULiege, Belgium. S.L-P and J.P. are research associate and research director of the belgian F.R.S.-FNRS, respectively. M.G. has a PhD fellowship from Walloon Region. N.P is MD, PhD in Medical sciences, specialized in internal medicine, endocrino-diabetology, full professor at ULiege, Belgium. Figures were composed with Servier Medical Art by Servier. Servier Medical Art by Servier is licensed under the Creative Commons Attribution 3.0 Unported License. To view a copy of this license, visit http://creativecommons.org/ licenses/by/3.0/ or send a letter to Creative Commons, PO Box 1866, Mountain View, CA 94042, USA.

\section{Author contributions}

M.G. and S.L.-P. conceived, designed and wrote the manuscript.
Each author revised and approved the manuscript.

\section{References}

[1] S.J. Singer, G.L. Nicolson, The fluid mosaic model of the structure of cell membranes, Science 175 (1972) 720-731, http://dx.doi.org/10.1126/science.175. 4023.720.

[2] D. Chandler, Interfaces and the driving force of hydrophobic assembly, Nature 437 (2005), http://dx.doi.org/10.1038/nature04162 nature04162.

[3] S. Ray, A. Kassan, A.R. Busija, P. Rangamani, H.H. Patel, The plasma membrane as a capacitor for energy and metabolism, Am. J. Physiol. - Cell Physiol. 310 (2016) C181-C192, http://dx.doi.org/10.1152/ajpcell.00087.2015.

[4] S. Ladha, The lipid organisation of the cell membrane, Grasas Aceites 51 (2000) $56-65$.

[5] D. Meyer zu Heringdorf, K.H. Jakobs, Lysophospholipid receptors: signalling, pharmacology and regulation by lysophospholipid metabolism, Biochim. Biophys. Acta 1768 (2007) 923-940, http://dx.doi.org/10.1016/j.bbamem.2006.09.026.

[6] J.E. Vance, Phospholipid synthesis and transport in mammalian cells, Traffic 16 (2015) 1-18, http://dx.doi.org/10.1111/tra.12230.

[7] V.A. Frolov, A.V. Shnyrova, J. Zimmerberg, Lipid polymorphisms and membrane shape, Cold Spring Harb. Perspect. Biol. 3 (2011), http://dx.doi.org/10.1101/ cshperspect.a004747.

[8] D. Marsh, Lateral pressure profile, spontaneous curvature frustration, and the in corporation and conformation of proteins in membranes, Biophys. J. 93 (2007) 3884-3899, http://dx.doi.org/10.1529/biophysj.107.107938.

[9] J.C.M. Holthuis, A.K. Menon, Lipid landscapes and pipelines in membrane homeostasis, Nature 510 (2014), http://dx.doi.org/10.1038/nature13474 nature13474.

[10] M.A.O. Magalhaes, M. Glogauer, Pivotal advance: phospholipids determine net membrane surface charge resulting in differential localization of active Rac1 and Rac2, J. Leukoc. Biol. 87 (2010) 545-555, http://dx.doi.org/10.1189/jlb. 0609390.

[11] N. Fuller, R.P. Rand, The influence of lysolipids on the spontaneous curvature and bending elasticity of phospholipid membranes, Biophys. J. 81 (2001) 243-254, http://dx.doi.org/10.1016/S0006-3495(01)75695-0.

[12] E. Fahy, S. Subramaniam, H.A. Brown, C.K. Glass, A.H. Merrill, R.C. Murphy, C.R.H. Raetz, D.W. Russell, Y. Seyama, W. Shaw, T. Shimizu, F. Spener, G. van Meer, M.S. VanNieuwenhze, S.H. White, J.L. Witztum, E.A. Dennis, A comprehensive classification system for lipids, J. Lipid Res. 46 (2005) 839-862, http://dx. doi.org/10.1194/jlr.E400004-JLR200.

[13] E. Fahy, S. Subramaniam, R.C. Murphy, M. Nishijima, C.R.H. Raetz, T. Shimizu, F. Spener, G. van Meer, M.J.O. Wakelam, E.A. Dennis, Update of the LIPID MAPS comprehensive classification system for lipids, J. Lipid Res. 50 (2009) S9-S14, http://dx.doi.org/10.1194/jlr.R800095-JLR200.

[14] T. Řezanka, K. Sigler, Odd-numbered very-long-chain fatty acids from the microbial, animal and plant kingdoms, Prog. Lipid Res. 48 (2009) 206-238, http://dx. doi.org/10.1016/j.plipres.2009.03.003.

[15] A.C. Rustan, C.A. Drevon, Fatty acids: structures and properties, John Wiley \& Sons, Ltd. John Wiley \& Sons, Ltd., Chichester, 2005, , http://dx.doi.org/10.1038/ npg.els.0003894.

[16] J.P. Slotte, Biological functions of sphingomyelins, Prog. Lipid Res. 52 (2013) 424-437, http://dx.doi.org/10.1016/j.plipres.2013.05.001.

[17] J. Aittoniemi, P.S. Niemelä, M.T. Hyvönen, M. Karttunen, I. Vattulainen, Insight into the putative specific interactions between cholesterol, sphingomyelin, and palmitoyl-oleoyl phosphatidylcholine, Biophys. J. 92 (2007) 1125-1137, http:// dx.doi.org/10.1529/biophysj.106.088427.

[18] C. Hofsäß, E. Lindahl, O. Edholm, Molecular dynamics simulations of phospholipid bilayers with cholesterol, Biophys. J. 84 (2003) 2192-2206.

[19] D.S. Schwarz, M.D. Blower, The endoplasmic reticulum: structure, function and response to cellular signaling, Cell. Mol. Life Sci. 73 (2016) 79-94, http://dx.doi. org/10.1007/s00018-015-2052-6.

[20] S. Gulati, Y. Liu, A.B. Munkacsi, L. Wilcox, S.L. Sturley, Sterols and sphingolipids: dynamic duo or partners in crime? Prog. Lipid Res. 49 (2010) 353-365, http://dx. doi.org/10.1016/j.plipres.2010.03.003.

[21] G. van Meer, A.I.P.M. de Kroon, Lipid map of the mammalian cell, J. Cell Sci. 124 (2011) 5-8, http://dx.doi.org/10.1242/jcs.071233.

[22] J.C.M. Holthuis, T. Pomorski, R.J. Raggers, H. Sprong, G.V. Meer, The organizing potential of sphingolipids in intracellular membrane transport, Physiol. Rev. 81 (2001) 1689-1723.

[23] G. van Meer, D.R. Voelker, G.W. Feigenson, Membrane lipids: where they are and how they behave, Nat. Rev. Mol. Cell Biol. 9 (2008) 112-124, http://dx.doi.org/ $10.1038 / \mathrm{nrm} 2330$.

[24] J.F. Strauss, T. Kishida, L.K. Christenson, T. Fujimoto, H. Hiroi, START domain proteins and the intracellular trafficking of cholesterol in steroidogenic cells, Mol. Cell. Endocrinol. 202 (2003) 59-65, http://dx.doi.org/10.1016/S0303-7207(03) 00063-7.

[25] F. Wilfling, J.T. Haas, T.C. Walther, R.V. Farese, Lipid droplet biogenesis, Curr. Opin. Cell Biol. 29 (2014) 39-45, http://dx.doi.org/10.1016/j.ceb.2014.03.008.

[26] A.R. Thiam, R.V. Farese, T.C. Walther, The biophysics and cell biology of lipid droplets, Nat. Rev. Mol. Cell Biol. 14 (2013) 775-786, http://dx.doi.org/10.1038/ nrm3699.

[27] Cambridge Advanced Learner's Dictionary, Cambridge University Press, 2008.

[28] S.L. Veatch, S.L. Keller, Separation of liquid phases in giant vesicles of ternary mixtures of phospholipids and cholesterol, Biophys. J. 85 (2003) 3074-3083.

[29] H.-J. Kaiser, D. Lingwood, I. Levental, J.L. Sampaio, L. Kalvodova, L. Rajendran, 
K. Simons, Order of lipid phases in model and plasma membranes, Proc. Natl. Acad. Sci. U.S.A. 106 (2009) 16645-16650, http://dx.doi.org/10.1073/pnas. 0908987106.

[30] T.-Y. Wang, J.R. Silvius, Cholesterol does not induce segregation of liquid-ordered domains in bilayers modeling the inner leaflet of the plasma membrane, Biophys. J. 81 (2001) 2762-2773, http://dx.doi.org/10.1016/S0006-3495(01)75919-X.

[31] G. Weber, F.J. Farris, Synthesis and spectral properties of a hydrophobic fluorescent probe: 6-propionyl-2-(dimethylamino)naphthalene, Biochemistry (Moscow) 18 (1979) 3075-3078, http://dx.doi.org/10.1021/bi00581a025.

[32] L.A. Bagatolli, To see or not to see: lateral organization of biological membranes and fluorescence microscopy, Biochim. Biophys. Acta 1758 (2006) 1541-1556, http://dx.doi.org/10.1016/j.bbamem.2006.05.019.

[33] F.M. Harris, K.B. Best, J.D. Bell, Use of laurdan fluorescence intensity and polarization to distinguish between changes in membrane fluidity and phospholipid order, Biochim. Biophys. Acta 1565 (2002) 123-128, http://dx.doi.org/10.1016/ S0005-2736(02)00514-X.

[34] S.A. Sanchez, M.A. Tricerri, E. Gratton, Laurdan generalized polarization fluc tuations measures membrane packing micro-heterogeneity in vivo, Proc. Natl Acad. Sci. U.S.A. 109 (2012) 7314-7319, http://dx.doi.org/10.1073/pnas. 1118288109.

[35] L.J. Pike, Rafts defined: a report on the keystone symposium on lipid rafts and cell function, J. Lipid Res. 47 (2006) 1597-1598, http://dx.doi.org/10.1194/jlr. E600002-JLR200.

[36] X.L. Guan, C.M. Souza, H. Pichler, G. Dewhurst, O. Schaad, K. Kajiwara, H. Wakabayashi, T. Ivanova, G.A. Castillon, M. Piccolis, F. Abe, R. Loewith, K. Funato, M.R. Wenk, H. Riezman, Functional interactions between sphingolipids and sterols in biological membranes regulating cell physiology, Mol. Biol. Cell. 20 (2009) 2083-2095, http://dx.doi.org/10.1091/mbc.E08-11-1126.

[37] B. Ramstedt, J.P. Slotte, Interaction of cholesterol with sphingomyelins and acylchain-matched phosphatidylcholines: a comparative study of the effect of the chain length, Biophys. J. 76 (1999) 908-915.

[38] I. Levental, M. Grzybek, K. Simons, Greasing their way: lipid modifications determine protein association with membrane rafts, Biochemistry (Moscow) 49 (2010) 6305-6316, http://dx.doi.org/10.1021/bi100882y.

[39] M.A. Surma, C. Klose, D. Peng, M. Shales, C. Mrejen, A. Stefanko, H. Braberg, D.E. Gordon, D. Vorkel, C.S. Ejsing, R. Farese, K. Simons, N.J. Krogan, R. Ernst, A lipid E-MAP identifies Ubx2 as a critical regulator of lipid saturation and lipid bilayer stress, Mol. Cell. 51 (2013) 519-530, http://dx.doi.org/10.1016/j.molcel. 2013.06.014

[40] B.B. Diaz-Rohrer, K.R. Levental, K. Simons, I. Levental, Membrane raft association is a determinant of plasma membrane localization, Proc. Natl. Acad. Sci. 111 (2014) 8500-8505, http://dx.doi.org/10.1073/pnas.1404582111.

[41] M. Fritzsche, C. Erlenkämper, E. Moeendarbary, G. Charras, K. Kruse, Actin kinetics shapes cortical network structure and mechanics, Sci. Adv. 2 (2016) e1501337, http://dx.doi.org/10.1126/sciadv.1501337.

[42] D.V. Köster, S. Mayor, Cortical actin and the plasma membrane: inextricably in tertwined, Curr. Opin. Cell Biol. 38 (2016) 81-89, http://dx.doi.org/10.1016/j. ceb.2016.02.021.

[43] D. Lingwood, B. Binnington, T. Róg, I. Vattulainen, M. Grzybek, Ü. Coskun, C.A. Lingwood, K. Simons, Cholesterol modulates glycolipid conformation and receptor activity, Nat. Chem. Biol. 7 (2011), http://dx.doi.org/10.1038/ nchembio.551 nchembio.51.

[44] A. Laganowsky, E. Reading, T.M. Allison, M.B. Ulmschneider, M.T. Degiacomi, A.J. Baldwin, C.V. Robinson, Membrane proteins bind lipids selectively to modulate their structure and function, Nature 510 (2014), http://dx.doi.org/10.1038/ nature13419 nature13419.

[45] P. Varshney, V. Yadav, N. Saini, Lipid rafts in immune signalling: current progress and future perspective, Immunology 149 (2016) 13-24, http://dx.doi.org/10. 1111/imm.12617.

[46] S. Beissert, H.-T. He, A.-O. Hueber, A.C. Lellouch, D. Metze, A. Mehling, T.A. Luger, T. Schwarz, S. Grabbe, Impaired cutaneous immune responses in Thy1-deficient mice, J. Immunol. 161 (1998) 5296-5302.

[47] F. Ameer, L. Scandiuzzi, S. Hasnain, H. Kalbacher, N. Zaidi, De novo lipogenesis in health and disease, Metab. Clin. Exp. 63 (2014) 895-902, http://dx.doi.org/10. 1016/j.metabol.2014.04.003.

[48] F. Diraison, V. Yankah, D. Letexier, E. Dusserre, P. Jones, M. Beylot, Differences in the regulation of adipose tissue and liver lipogenesis by carbohydrates in humans, J. Lipid Res. 44 (2003) 846-853, http://dx.doi.org/10.1194/jlr.M200461-JLR200.

[49] I.J. Lodhi, X. Wei, C.F. Semenkovich, Lipoexpediency: de novo lipogenesis as a metabolic signal transmitter, Trends Endocrinol. Metab. 22 (2011) 1-8, http://dx. doi.org/10.1016/j.tem.2010.09.002.

[50] M.S. Strable, J.M. Ntambi, Genetic control of de novo lipogenesis: role in dietinduced obesity, Crit. Rev. Biochem. Mol. Biol. 45 (2010) 199-214, http://dx.doi. org/10.3109/10409231003667500.

[51] W. Shao, P.J. Espenshade, Expanding roles for SREBP in metabolism, Cell Metab. 16 (2012) 414-419, http://dx doi org/10.1016/j cmet 2012.09.002.

[52] M.A. Herman, O.D. Peroni, J. Villoria, M.R. Schön, N.A. Abumrad, M. Blüher, S. Klein, B.B. Kahn, A novel ChREBP isoform in adipose tissue regulates systemic glucose metabolism, Nature 484 (2012) 333-338, http://dx.doi.org/10.1038/ nature10986.

[53] H. Guillou, D. Zadravec, P.G.P. Martin, A. Jacobsson, The key roles of elongases and desaturases in mammalian fatty acid metabolism: insights from transgenic mice, Prog. Lipid Res. 49 (2010) 186-199, http://dx.doi.org/10.1016/j.plipres. 2009.12.002

[54] A. Jakobsson, R. Westerberg, A. Jacobsson, Fatty acid elongases in mammals: their regulation and roles in metabolism, Prog. Lipid Res. 45 (2006) 237-249, http:// dx.doi.org/10.1016/j.plipres.2006.01.004

[55] J. Ye, R.A. DeBose-Boyd, Regulation of cholesterol and fatty acid synthesis, Cold Spring Harb. Perspect. Biol. 3 (2011) a004754, http://dx.doi.org/10.1101/ cshperspect.a004754.

[56] M.S. Brown, J.L. Goldstein, The SREBP pathway: regulation of cholesterol metabolism by proteolysis of a membrane-bound transcription factor, Cell 89 (1997) 331-340, http://dx.doi.org/10.1016/S0092-8674(00)80213-5.

[57] L.-P. Sun, L. Li, J.L. Goldstein, M.S. Brown, Insig required for sterol-mediated inhibition of scap/SREBP binding to COPII proteins in vitro, J. Biol. Chem. 280 (2005) 26483-26490, http://dx.doi.org/10.1074/jbc.M504041200.

[58] R.A. DeBose-Boyd, M.S. Brown, W.-P. Li, A. Nohturfft, J.L. Goldstein, P.J. Espenshade, Transport-dependent proteolysis of SREBP: relocation of site-1 protease from golgi to ER obviates the need for SREBP transport to golgi, Cell 99 (1999) 703-712, http://dx.doi.org/10.1016/S0092-8674(00)81668-2.

[59] A. Nohturfft, D. Yabe, J.L. Goldstein, M.S. Brown, P.J. Espenshade, Regulated step in cholesterol feedback localized to budding of SCAP from ER membranes, Cell 102 (2000) 315-323, http://dx.doi.org/10.1016/S0092-8674(00)00037-4.

[60] J.D. Horton, N.A. Shah, J.A. Warrington, N.N. Anderson, S.W. Park, M.S. Brown J.L. Goldstein, Combined analysis of oligonucleotide microarray data from transgenic and knockout mice identifies direct SREBP target genes, Proc. Natl. Acad. Sci. 100 (2003) 12027-12032, http://dx.doi.org/10.1073/pnas.1534923100.

[61] X. Hua, A. Nohturfft, J.L. Goldstein, M.S. Brown, Sterol resistance in CHO cells traced to point mutation in SREBP cleavage-activating protein, Cell 87 (1996) 415-426, http://dx.doi.org/10.1016/S0092-8674(00)81362-8.

[62] J. Pai, O. Guryev, M.S. Brown, J.L. Goldstein, Differential stimulation of cholesterol and unsaturated fatty acid biosynthesis in cells expressing individual nuclear sterol regulatory element-binding proteins, J. Biol. Chem. 273 (1998) 26138-26148, http://dx.doi.org/10.1074/jbc.273.40.26138.

[63] R.A. DeBose-Boyd, J. Ou, J.L. Goldstein, M.S. Brown, Expression of sterol regulatory element-binding protein 1c (SREBP-1c) mRNA in rat hepatoma cells requires endogenous LXR ligands, Proc. Natl. Acad. Sci. U.S.A. 98 (2001) $1477-1482$.

[64] J. Ou, H. Tu, B. Shan, A. Luk, R.A. DeBose-Boyd, Y. Bashmakov, J.L. Goldstein, M.S. Brown, Unsaturated fatty acids inhibit transcription of the sterol regulatory element-binding protein-1c (SREBP-1c) gene by antagonizing ligand-dependent activation of the LXR, Proc. Natl. Acad. Sci. U.S.A. 98 (2001) 6027-6032, http:// dx.doi.org/10.1073/pnas.111138698.

[65] J.J. Repa, G. Liang, J. Ou, Y. Bashmakov, J.-M.A. Lobaccaro, I. Shimomura, B. Shan, M.S. Brown, J.L. Goldstein, D.J. Mangelsdorf, Regulation of mouse sterol regulatory element-binding protein-1c gene (SREBP-1c) by oxysterol receptors, LXR $\alpha$ and LXR $\beta$, Genes Dev. 14 (2000) 2819-2830, http://dx.doi.org/10.1101/ gad.844900.

[66] V.C. Hannah, J. Ou, A. Luong, J.L. Goldstein, M.S. Brown, Unsaturated fatty acids down-regulate SREBP isoforms 1a and 1c by two mechanisms in HEK-293 cells, J. Biol. Chem. 276 (2001) 4365-4372, http://dx.doi.org/10.1074/jbc.M007273200.

[67] Y. Ikeda, G.N. DeMartino, M.S. Brown, J.N. Lee, J.L. Goldstein, J. Ye, Regulated endoplasmic reticulum-associated degradation of a polytopic protein, J. Biol. Chem. 284 (2009) 34889-34900, http://dx.doi.org/10.1074/jbc.M109.044875.

[68] J.N. Lee, B. Song, R.A. DeBose-Boyd, J. Ye, Sterol-regulated degradation of Insig-1 mediated by the membrane-bound ubiquitin ligase gp78, J. Biol. Chem. 281 (2006) 39308-39315, http://dx.doi.org/10.1074/jbc.M608999200.

[69] J.N. Lee, X. Zhang, J.D. Feramisco, Y. Gong, J. Ye, Unsaturated fatty acids inhibit proteasomal degradation of Insig-1 at a postubiquitination step, J. Biol. Chem. 283 (2008) 33772-33783, http://dx.doi.org/10.1074/jbc.M806108200.

[70] A. Yamashita, Y. Hayashi, N. Matsumoto, Y. Nemoto-Sasaki, S. Oka, T. Tanikawa, T. Sugiura, Glycerophosphate/acylglycerophosphate acyltransferases, Biology 3 (2014) 801-830, http://dx.doi.org/10.3390/biology3040801.

[71] K. Reue, The lipin family: mutations and metabolism, Curr. Opin. Lipidol. 20 (2009) 165-170, http://dx.doi.org/10.1097/MOL.0b013e32832adee5.

[72] C.-L.E. Yen, S.J. Stone, S. Koliwad, C. Harris, R.V. Farese, Thematic review series: glycerolipids. DGAT enzymes and triacylglycerol biosynthesis, J. Lipid Res. 49 (2008) 2283-2301, http://dx.doi.org/10.1194/jlr.R800018-JLR200.

[73] P. Fagone, S. Jackowski, Phosphatidylcholine and the CDP-Choline Cycle, Biochim. Biophys. Acta 2013 (1831) 523-532, http://dx.doi.org/10.1016/j. bbalip.2012.09.009.

[74] D.E. Vance, Phospholipid methylation in mammals: from biochemistry to physiological function, Biochim. Biophys. Acta 2014 (1838) 1477-1487, http://dx doi.org/10.1016/j.bbamem.2013.10.018.

[75] H. Shindou, D. Hishikawa, T. Harayama, M. Eto, T. Shimizu, Generation of membrane diversity by lysophospholipid acyltransferases, J. Biochem. (Tokyo) 154 (2013) 21-28, http://dx.doi.org/10.1093/jb/mvt048.

[76] W.E.M. Lands, Metabolism of glycerolipides: a comparison of lecithin and triglyceride synthesis, J. Biol. Chem. 231 (1958) 883-888.

[77] W.E.M. Lands, Stories about acyl chains, Biochim. Biophys. Acta 1483 (2000) 1-14, http://dx.doi.org/10.1016/S1388-1981(99)00177-8.

[78] T. Shimizu, Lipid mediators in health and disease: enzymes and receptors as therapeutic targets for the regulation of immunity and inflammation, Annu. Rev. Pharmacol. Toxicol. 49 (2009) 123-150, http://dx.doi.org/10.1146/annurev. pharmtox.011008.145616.

[79] H. Shindou, T. Shimizu, Acyl-CoA: lysophospholipid acyltransferases, J. Biol. Chem. 284 (2009) 1-5, http://dx.doi.org/10.1074/jbc.R800046200.

[80] D. Hishikawa, T. Hashidate, T. Shimizu, H. Shindou, Diversity and function of membrane glycerophospholipids generated by the remodeling pathway in mammalian cells, J. Lipid Res. 55 (2014) 799-807, http://dx.doi.org/10.1194/jlr. R046094.

[81] H. Shindou, D. Hishikawa, H. Nakanishi, T. Harayama, S. Ishii, R. Taguchi, 
T. Shimizu, A single enzyme catalyzes both platelet-activating factor production and membrane biogenesis of inflammatory cells cloning and characterization of acetyl-CoA:LYSO-PAF acetyltransferase, J. Biol. Chem. 282 (2007) 6532-6539, http://dx.doi.org/10.1074/jbc.M609641200.

[82] O. Demeure, F. Lecerf, C. Duby, C. Desert, S. Ducheix, H. Guillou, S. Lagarrigue, Regulation of LPCAT3 by LXR, Gene 470 (2011) 7-11, http://dx.doi.org/10.1016/ j.gene.2010.09.002

[83] M. Eto, H. Shindou, A. Koeberle, T. Harayama, K. Yanagida, T. Shimizu, Lysophosphatidylcholine acyltransferase 3 Is the key enzyme for incorporating arachidonic acid into glycerophospholipids during adipocyte differentiation, Int J. Mol. Sci. 13 (2012) 16267-16280, http://dx.doi.org/10.3390/ijms131216267.

[84] D. Hishikawa, H. Shindou, S. Kobayashi, H. Nakanishi, R. Taguchi, T. Shimizu, Discovery of a lysophospholipid acyltransferase family essential for membrane asymmetry and diversity, Proc. Natl. Acad. Sci. U.S.A. 105 (2008) 2830-2835, http://dx.doi.org/10.1073/pnas.0712245105.

[85] Y. Zhao, Y.-Q. Chen, T.M. Bonacci, D.S. Bredt, S. Li, W.R. Bensch, D.E. Moller, M. Kowala, R.J. Konrad, G. Cao, Identification and characterization of a major liver lysophosphatidylcholine acyltransferase, J. Biol. Chem. 283 (2008) 8258-8265, http://dx.doi.org/10.1074/jbc.M710422200.

[86] S. Matsuda, T. Inoue, H.-C. Lee, N. Kono, F. Tanaka, K. Gengyo-Ando, S. Mitani, H. Arai, Member of the membrane-bound O-acyltransferase (MBOAT) family encodes a lysophospholipid acyltransferase with broad substrate specificity, Genes Cells Devoted Mol. Cell. Mech. 13 (2008) 879-888, http://dx.doi.org/10.1111/j. 1365-2443.2008.01212.x.

[87] X. Rong, C.J. Albert, C. Hong, M.A. Duerr, B.T. Chamberlain, E.J. Tarling, A. Ito, J. Gao, B. Wang, P.A. Edwards, M.E. Jung, D.A. Ford, P. Tontonoz, LXRs regulate ER stress and inflammation through dynamic modulation of membrane phospholipid composition, Cell Metab. 18 (2013) 685-697, http://dx.doi.org/10. 1016/j.cmet.2013.10.002.

[88] R. Dawaliby, C. Trubbia, C. Delporte, C. Noyon, J.-M. Ruysschaert, P.V. Antwerpen, C. Govaerts, Phosphatidylethanolamine is a key regulator of membrane fluidity in eukaryotic cells, J. Biol. Chem. 291 (2016) 3658-3667, http://dx.doi.org/10.1074/jbc.M115.706523.

[89] M.D. Jensen, Fate of fatty acids at rest and during exercise: regulatory mechanisms, Acta Physiol. Scand. 178 (2003) 385-390, http://dx.doi.org/10.1046/j. 1365-201X.2003.01167.x.

[90] Y. Li, M. Ge, L. Ciani, G. Kuriakose, E.J. Westover, M. Dura, D.F. Covey, J.H. Freed, F.R. Maxfield, J. Lytton, I. Tabas, Enrichment of endoplasmic reticulum with cholesterol inhibits sarcoplasmic-endoplasmic reticulum calcium ATPase-2b activity in parallel with increased order of membrane lipids: implications for depletion of endoplasmic reticulum calcium stores and apoptosis in cholesterolloaded macrophages, J. Biol. Chem. 279 (2004) 37030-37039, http://dx.doi.org/ 10.1074/jbc.M405195200.

[91] F. Cornelius, M. Habeck, R. Kanai, C. Toyoshima, S.J.D. Karlish, General and specific lipid-protein interactions in Na, K-ATPase, Biochim. Biophys. Acta 2015 (1848) 1729-1743, http://dx.doi.org/10.1016/j.bbamem.2015.03.012.

[92] S.K. Abbott, P.L. Else, T.A. Atkins, A.J. Hulbert, Fatty acid composition of membrane bilayers: importance of diet polyunsaturated fat balance, Biochim. Biophys. Acta 2012 (1818) 1309-1317, http://dx.doi.org/10.1016/j.bbamem.2012.01. 011

[93] E.K. Lund, L.J. Harvey, S. Ladha, D.C. Clark, I.T. Johnson, Effects of dietary fish oil supplementation on the phospholipid composition and fluidity of cell membranes from human volunteers, Ann. Nutr. Metab. 43 (1999) 290-300.

[94] A. Andersson, C. Nälsén, S. Tengblad, B. Vessby, Fatty acid composition of skeletal muscle reflects dietary fat composition in humans, Am. J. Clin. Nutr. 76 (2002) 1222-1229.

[95] S. Kersten, Mechanisms of nutritional and hormonal regulation of lipogenesis, EMBO Rep. 2 (2001) 282-286, http://dx.doi.org/10.1093/embo-reports/kve071.

[96] E. Rysman, K. Brusselmans, K. Scheys, L. Timmermans, R. Derua, S. Munck, P.P. Van Veldhoven, D. Waltregny, V.W. Daniëls, J. Machiels, F. Vanderhoydonc, K. Smans, E. Waelkens, G. Verhoeven, J.V. Swinnen, De novo lipogenesis protects cancer cells from free radicals and chemotherapeutics by promoting membrane lipid saturation, Cancer Res. 70 (2010) 8117-8126, http://dx.doi.org/10.1158/ 0008-5472.CAN-09-3871.

[97] S. Fu, L. Yang, P. Li, O. Hofmann, L. Dicker, W. Hide, X. Lin, S.M. Watkins, A.R. Ivanov, G.S. Hotamisligil, Aberrant lipid metabolism disrupts calcium homeostasis causing liver endoplasmic reticulum stress in obesity, Nature 473 (2011) 528-531, http://dx.doi.org/10.1038/nature09968.

[98] K.G.M.M. Alberti, R.H. Eckel, S.M. Grundy, P.Z. Zimmet, J.I. Cleeman, K.A. Donato, J.-C. Fruchart, W.P.T. James, C.M. Loria, S.C. Smith, International Diabetes Federation Task Force on Epidemiology and Prevention, Hational Heart, Lung, and Blood Institute, American Heart Association, World Heart Federation, International Atherosclerosis Society, International Association for the Study of Obesity, Harmonizing the metabolic syndrome: a joint interim statement of the International Diabetes Federation Task Force on Epidemiology and Prevention; National Heart, Lung, and Blood Institute; American Heart Association; World Heart Federation; International Atherosclerosis Society; and International Association for the Study of Obesity, Circulation 120 (2009) 1640-1645, http:// dx.doi.org/10.1161/CIRCULATIONAHA.109.192644.

[99] F. Soriguer, S. García-Serrano, J.M. García-Almeida, L. Garrido-Sánchez, J. GarcíaArnés, F.J. Tinahones, I. Cardona, J. Rivas-Marín, J.L. Gallego-Perales, E. GarcíaFuentes, Changes in the serum composition of free-fatty acids during an intravenous glucose tolerance test, Obes. Silver Spring MD 17 (2009) 10-15, http:// dx.doi.org/10.1038/oby.2008.475.

[100] M. Pilon, Revisiting the membrane-centric view of diabetes, Lipids Health Dis. 15 (2016), http://dx.doi.org/10.1186/s12944-016-0342-0.
[101] P.M. Clifton, P.J. Nestel, Relationship between plasma insulin and erythrocyte fatty acid composition, Prostaglandins Leukot. Essent. Fatty Acids 59 (1998) 191-194.

[102] M. Borkman, L.H. Storlien, D.A. Pan, A.B. Jenkins, D.J. Chisholm, L.V. Campbell, The relation between insulin sensitivity and the fatty-acid composition of skeletalmuscle phospholipids, N. Engl. J. Med. 328 (1993) 238-244, http://dx.doi.org/10. 1056/NEJM199301283280404.

[103] E. Bakan, A. Yildirim, N. Kurtul, M.F. Polat, H. Dursun, K. Cayir, Effects of type 2 diabetes mellitus on plasma fatty acid composition and cholesterol content of erythrocyte and leukocyte membranes, Acta Diabetol. 43 (2006) 109-113, http:// dx.doi.org/10.1007/s00592-007-0224-4.

[104] N.G. Forouhi, A. Koulman, S.J. Sharp, F. Imamura, J. Kröger, M.B. Schulze, F.L. Crowe, J.M. Huerta, M. Guevara, J.W.J. Beulens, G.J. van Woudenbergh, L. Wang, K. Summerhill, J.L. Griffin, E.J.M. Feskens, P. Amiano, H. Boeing, F. Clavel-Chapelon, L. Dartois, G. Fagherazzi, P.W. Franks, C. Gonzalez, M.U. Jakobsen, R. Kaaks, T.J. Key, K.-T. Khaw, T. Kühn, A. Mattiello, P.M. Nilsson, K. Overvad, V. Pala, D. Palli, J.R. Quirós, O. Rolandsson, N. Roswall, C. Sacerdote, M.-J. Sánchez, N. Slimani, A.M.W. Spijkerman, A. Tjonneland, M.-J. Tormo, R. Tumino, D.L. van der A, Y.T. van der Schouw, C. Langenberg, E. Riboli, N.J. Wareham, Differences in the prospective association between individual plasma phospholipid saturated fatty acids and incident type 2 diabetes: the EPICInterAct case-cohort study, Lancet Diabetes Endocrinol. 2 (2014) 810-818, http:// dx.doi.org/10.1016/S2213-8587(14)70146-9.

[105] J. Kröger, S. Jacobs, E.H.J.M. Jansen, A. Fritsche, H. Boeing, M.B. Schulze, Erythrocyte membrane fatty acid fluidity and risk of type 2 diabetes in the EPIC Potsdam study, Diabetologia 58 (2015) 282-289, http://dx.doi.org/10.1007/ s00125-014-3421-7.

[106] J.S. Elmendorf, Fluidity of insulin action, Mol. Biotechnol. 27 (2004) 127-138, http://dx.doi.org/10.1385/MB:27:2:127.

[107] B.H. Ginsberg, T.J. Brown, I. Simon, A.A. Spector, Effect of the membrane lipid environment on the properties of insulin receptors, Diabetes 30 (1981) 773-780.

[108] R.N.M. Weijers, Lipid composition of cell membranes and its relevance in type 2 diabetes mellitus, Curr. Diabetes Rev. 8 (2012) 390-400.

[109] M.K. Vidya, V.G. Kumar, V. Sejian, M. Bagath, G. Krishnan, R. Bhatta, Toll-like receptors: significance, ligands, signaling pathways, and functions in mammals, Int. Rev. Immunol. (2017) 1-17, http://dx.doi.org/10.1080/08830185.2017. 1380200 .

[110] A. Steimle, I.B. Autenrieth, J.-S. Frick, Structure and function: lipid A modifications in commensals and pathogens, Int. J. Med. Microbiol. IJMM 306 (2016) 290-301, http://dx.doi.org/10.1016/j.ijmm.2016.03.001.

[111] P. Mertins, D. Przybylski, N. Yosef, J. Qiao, K. Clauser, R. Raychowdhury, T.M. Eisenhaure, T. Maritzen, V. Haucke, T. Satoh, S. Akira, S.A. Carr, A. Regev, N. Hacohen, N. Chevrier, An integrative framework reveals signaling-to-transcription events in toll-like receptor signaling, Cell Rep. 19 (2017) 2853-2866, http://dx.doi.org/10.1016/j.celrep.2017.06.016.

[112] N.N. Kuzmich, K.V. Sivak, V.N. Chubarev, Y.B. Porozov, T.N. SavateevaLyubimova, F. Peri, TLR4 signaling pathway modulators as potential therapeutics in inflammation and sepsis, Vaccines 5 (2017), http://dx.doi.org/10.3390/ vaccines5040034

[113] H. Shi, M.V. Kokoeva, K. Inouye, I. Tzameli, H. Yin, J.S. Flier, TLR4 links innate immunity and fatty acid-induced insulin resistance, J. Clin. Invest. 116 (2006) 3015-3025, http://dx.doi.org/10.1172/JCI28898.

[114] A.C. Manolakis, A.N. Kapsoritakis, E.K. Tiaka, A. Sidiropoulos, A. Gerovassili, M. Satra, D. Vamvakopoulou, F. Tsiopoulos, N. Papanas, I. Skoularigis, S.P. Potamianos, N. Vamvakopoulos, TLR4 gene polymorphisms: evidence for protection against type 2 diabetes but not for diabetes-associated ischaemic heart disease, Eur. J. Endocrinol. 165 (2011) 261-267, http://dx.doi.org/10.1530/EJE11-0280.

[115] B.S. Park, D.H. Song, H.M. Kim, B.-S. Choi, H. Lee, J.-O. Lee, The structural basis of lipopolysaccharide recognition by the TLR4-MD-2 complex, Nature 458 (2009) 1191-1195, http://dx.doi.org/10.1038/nature07830.

[116] S. Akira, S. Uematsu, O. Takeuchi, Pathogen recognition and innate immunity, Cell 124 (2006) 783-801, http://dx.doi.org/10.1016/j.cell.2006.02.015.

[117] A. Haziot, E. Ferrero, F. Köntgen, N. Hijiya, S. Yamamoto, J. Silver, C.L. Stewart, S.M. Goyert, Resistance to endotoxin shock and reduced dissemination of gramnegative bacteria in CD14-deficient mice, Immunity 4 (1996) 407-414.

[118] E. Ferrero, D. Jiao, B.Z. Tsuberi, L. Tesio, G.W. Rong, A. Haziot, S.M. Goyert, Transgenic mice expressing human CD14 are hypersensitive to lipopolysaccharide, Proc. Natl. Acad. Sci. U.S.A. 90 (1993) 2380-2384.

[119] Z. Jiang, P. Georgel, X. Du, L. Shamel, S. Sovath, S. Mudd, M. Huber, C. Kalis, S. Keck, C. Galanos, M. Freudenberg, B. Beutler, CD14 is required for MyD88independent LPS signaling, Nat. Immunol. 6 (2005) 565-570, http://dx.doi.org/ 10.1038/ni1207.

[120] J. da Silva Correia, K. Soldau, U. Christen, P.S. Tobias, R.J. Ulevitch, Lipopolysaccharide is in close proximity to each of the proteins in its membrane receptor complex. Transfer from CD14 to TLR4 and MD-2, J. Biol. Chem. 276 (2001) 21129-21135, http://dx.doi.org/10.1074/jbc.M009164200.

[121] K.A. Fitzgerald, D.C. Rowe, D.T. Golenbock, Endotoxin recognition and signal transduction by the TLR4/MD2-complex, Microbes Infect. 6 (2004) 1361-1367, http://dx.doi.org/10.1016/j.micinf.2004.08.015.

[122] M. Triantafilou, K. Miyake, D.T. Golenbock, K. Triantafilou, Mediators of innate immune recognition of bacteria concentrate in lipid rafts and facilitate lipopolysaccharide-induced cell activation, J. Cell Sci. 115 (2002) 2603-2611.

[123] M. Triantafilou, S. Morath, A. Mackie, T. Hartung, K. Triantafilou, Lateral diffusion of Toll-like receptors reveals that they are transiently confined within lipid rafts on the plasma membrane, J. Cell Sci. 117 (2004) 4007-4014, http://dx.doi.org/10. 
$1242 /$ jcs. 01270 .

[124] S. Dhungana, B.A. Merrick, K.B. Tomer, M.B. Fessler, Quantitative proteomic analysis of macrophage rafts reveals compartmentalized activation of the proteasome and of proteasome-mediated ERK activation in response to lipopolysaccharide, Mol. Cell. Proteomics MCP 8 (2009) 201-213, http://dx.doi.org/10. 1074/mcp.M800286-MCP200.

[125] A. Płóciennikowska, A. Hromada-Judycka, K. Borzęcka, K. Kwiatkowska, Co-operation of TLR4 and raft proteins in LPS-induced pro-inflammatory signaling, Cell. Mol. Life Sci. CMLS 72 (2015) 557-581, http://dx.doi.org/10.1007/s00018-0141762-5.

[126] M. Koseki, K.-I. Hirano, D. Masuda, C. Ikegami, M. Tanaka, A. Ota, J.C. Sandoval, Y. Nakagawa-Toyama, S.B. Sato, T. Kobayashi, Y. Shimada, Y. Ohno-Iwashita, F. Matsuura, I. Shimomura, S. Yamashita, Increased lipid rafts and accelerated lipopolysaccharide-induced tumor necrosis factor-alpha secretion in Abca1-deficient macrophages, J. Lipid Res. 48 (2007) 299-306, http://dx.doi.org/10.1194/ jlr.M600428-JLR200.

[127] L. Yvan-Charvet, C. Welch, T.A. Pagler, M. Ranalletta, M. Lamkanfi, S. Han, M. Ishibashi, R. Li, N. Wang, A.R. Tall, Increased inflammatory gene expression in ABC transporter-deficient macrophages: free cholesterol accumulation, increased signaling via toll-like receptors, and neutrophil infiltration of atherosclerotic lesions, Circulation 118 (2008) 1837-1847, http://dx.doi.org/10.1161/ CIRCULATIONAHA.108.793869.

[128] J.Y. Lee, K.H. Sohn, S.H. Rhee, D. Hwang, Saturated fatty acids, but not unsaturated fatty acids, induce the expression of cyclooxygenase-2 mediated through Toll-like receptor 4, J. Biol. Chem. 276 (2001) 16683-16689, http://dx.doi.org/ 10.1074/jbc.M011695200.

[129] S.W. Wong, M.-J. Kwon, A.M.K. Choi, H.-P. Kim, K. Nakahira, D.H. Hwang, Fatty acids modulate Toll-like receptor 4 activation through regulation of receptor dimerization and recruitment into lipid rafts in a reactive oxygen species-dependent manner, J. Biol. Chem. 284 (2009) 27384-27392, http://dx.doi.org/10.1074/jbc. M109.044065.

[130] K. Brandl, T. Glück, P. Hartmann, B. Salzberger, W. Falk, A designed TLR4/MD-2 complex to capture LPS, J. Endotoxin Res. 11 (2005) 197-206, http://dx.doi.org/ 10.1179/096805105X58670.

[131] C. Erridge, N.J. Samani, Saturated fatty acids do not directly stimulate Toll-like receptor signaling, Arterioscler. Thromb. Vasc. Biol. 29 (2009) 1944-1949, http:// dx.doi.org/10.1161/ATVBAHA.109.194050.

[132] D. Pal, S. Dasgupta, R. Kundu, S. Maitra, G. Das, S. Mukhopadhyay, S. Ray, S.S. Majumdar, S. Bhattacharya, Fetuin-A acts as an endogenous ligand of TLR4 to promote lipid-induced insulin resistance, Nat. Med. 18 (2012) 1279-1285, http:// dx.doi.org/10.1038/nm.2851.

[133] L.A. Velloso, F. Folli, M.J. Saad, TLR4 at the crossroads of nutrients, gut microbiota, and metabolic inflammation, Endocr. Rev. 36 (2015) 245-271, http://dx. doi.org/10.1210/er.2014-1100.

[134] D.H. Hwang, J.-A. Kim, J.Y. Lee, Mechanisms for the activation of Toll-like receptor $2 / 4$ by saturated fatty acids and inhibition by docosahexaenoic acid, Eur. J. Pharmacol. 785 (2016) 24-35, http://dx.doi.org/10.1016/j.ejphar.2016.04.024.

[135] R.G. Snodgrass, S. Huang, I.-W. Choi, J.C. Rutledge, D.H. Hwang, Inflammasomemediated secretion of IL-1 $\beta$ in human monocytes through TLR2 activation; modulation by dietary fatty acids, J. Immunol. 191 (2013) 4337-4347, http://dx.doi. org/10.4049/jimmunol.1300298.

[136] T.M. Stulnig, J. Huber, N. Leitinger, E.-M. Imre, P. Angelisová, P. Nowotny, W. Waldhäusl, Polyunsaturated eicosapentaenoic acid displaces proteins from membrane rafts by altering raft lipid composition, J. Biol. Chem. 276 (2001) 37335-37340, http://dx.doi.org/10.1074/jbc.M106193200.

[137] Y.-Y. Fan, L.H. Ly, R. Barhoumi, D.N. McMurray, R.S. Chapkin, Dietary doc osahexaenoic acid suppresses T cell protein kinase $\mathrm{C} \theta$ lipid raft recruitment and IL2 production, J. Immunol. 173 (2004) 6151-6160, http://dx.doi.org/10.4049/ jimmunol.173.10.6151.

[138] C.A. Rivera, L. Gaskin, G. Singer, J. Houghton, M. Allman, Western diet enhances hepatic inflammation in mice exposed to cecal ligation and puncture, BMC Physiol. 10 (2010) 20, http://dx.doi.org/10.1186/1472-6793-10-20.

[139] A. Ciesielska, K. Kwiatkowska, Modification of pro-inflammatory signaling by dietary components: the plasma membrane as a target, BioEssays News Rev. Mol. Cell. Dev. Biol. 37 (2015) 789-801, http://dx.doi.org/10.1002/bies.201500017.

[140] Y. Sakr, C. Madl, D. Filipescu, R. Moreno, J. Groeneveld, A. Artigas, K. Reinhart, J.-L. Vincent, Obesity is associated with increased morbidity but not mortality in critically ill patients, Intensive Care Med. 34 (2008) 1999-2009, http://dx.doi. org/10.1007/s00134-008-1243-0.

[141] P.D. Cani, R. Bibiloni, C. Knauf, A. Waget, A.M. Neyrinck, N.M. Delzenne, R. Burcelin, Changes in gut microbiota control metabolic endotoxemia-induced inflammation in high-fat diet-induced obesity and diabetes in mice, Diabetes. 57 (2008) 1470-1481, http://dx.doi.org/10.2337/db07-1403.

[142] A. Everard, C. Belzer, L. Geurts, J.P. Ouwerkerk, C. Druart, L.B. Bindels, Y. Guiot, M. Derrien, G.G. Muccioli, N.M. Delzenne, W.M. de Vos, P.D. Cani, Cross-talk between Akkermansia muciniphila and intestinal epithelium controls diet-induced obesity, Proc. Natl. Acad. Sci. U.S.A. 110 (2013) 9066-9071, http://dx.doi.org/10. 1073/pnas.1219451110.

[143] H. Plovier, A. Everard, C. Druart, C. Depommier, M. Van Hul, L. Geurts, J. Chilloux, N. Ottman, T. Duparc, L. Lichtenstein, A. Myridakis, N.M. Delzenne, J. Klievink, A. Bhattacharjee, K.C.H. van der Ark, S. Aalvink, L.O. Martinez, M.E. Dumas, D. Maiter, A. Loumaye, M.P. Hermans, J.-P. Thissen, C. Belzer, W.M. de Vos, P.D. Cani, A purified membrane protein from Akkermansia muciniphila or the pasteurized bacterium improves metabolism in obese and diabetic mice, Nat. Med. 23 (2017) 107-113, http://dx.doi.org/10.1038/nm.4236.

[144] J.C. Skou, The influence of some cations on an adenosine triphosphatase from peripheral nerves, Biochim. Biophys. Acta 23 (1957) 394-401, http://dx.doi.org/ 10.1016/0006-3002(57)90343-8.

[145] G. Blanco, R.W. Mercer, Isozymes of the Na-K-ATPase: heterogeneity in structure, diversity in function, Am. J. Physiol. 275 (1998) F633-650.

[146] R.L. Post, S. Kume, T. Tobin, B. Orcutt, A.K. Sen, Flexibility of an active center in sodium-plus-potassium adenosine triphosphatase, J. Gen. Physiol. 54 (1969) 306-326.

[147] G.E. Shull, J. Greeb, J.B. Lingrel, Molecular cloning of three distinct forms of the $\mathrm{Na}+, \mathrm{K}+$-ATPase alpha-subunit from rat brain, Biochemistry (Moscow) 25 (1986) $8125-8132$

[148] O.I. Shamraj, J.B. Lingrel, A putative fourth $\mathrm{Na}+$, K( +)-ATPase alpha-subunit gene is expressed in testis, Proc. Natl. Acad. Sci. U.S.A. 91 (1994) 12952-12956.

[149] J.P. Morth, B.P. Pedersen, M.S. Toustrup-Jensen, T.L.-M. Sørensen, J. Petersen J.P. Andersen, B. Vilsen, P. Nissen, Crystal structure of the sodium-potassium pump, Nature 450 (2007) 1043-1049, http://dx.doi.org/10.1038/nature06419.

[150] J.P. Morth, B.P. Pedersen, M.J. Buch-Pedersen, J.P. Andersen, B. Vilsen, M.G. Palmgren, P. Nissen, A structural overview of the plasma membrane $\mathrm{Na}+, \mathrm{K}$ +-ATPase and H +-ATPase ion pumps, Nat. Rev. Mol. Cell Biol. 12 (2011) 60-70, http://dx.doi.org/10.1038/nrm3031.

[151] M.V. Clausen, F. Hilbers, H. Poulsen, The structure and function of the Na, KATPase isoforms in health and disease, Front. Physiol. 8 (2017), http://dx.doi.org/ 10.3389/fphys.2017.00371

[152] A.Y. Bagrov, J.I. Shapiro, O.V. Fedorova, Endogenous cardiotonic steroids: physiology, pharmacology, and novel therapeutic targets, Pharmacol. Rev. 61 (2009) 9-38, http://dx.doi.org/10.1124/pr.108.000711.

[153] W. Schoner, G. Scheiner-Bobis, Endogenous and exogenous cardiac glycosides and their mechanisms of action, Am. J. Cardiovasc. Drugs 7 (2007) 173-189.

[154] M. Laursen, L. Yatime, P. Nissen, N.U. Fedosova, Crystal structure of the highaffinity $\mathrm{Na}+, \mathrm{K}+$-ATPase-ouabain complex with $\mathrm{Mg} 2+$ bound in the cation binding site, Proc. Natl. Acad. Sci. 110 (2013) 10958-10963, http://dx.doi.org/ 10.1073/pnas.1222308110.

[155] W.S. McMahon, H.H. Holzgrefe, J.D. Walker, R. Mukherjee, S.R. Arthur, M.J. Cavallo, M.J. Child, F.G. Spinale, Cellular basis for improved left ventricular pump function after digoxin therapy in experimental left ventricular failure, J. Am. Coll. Cardiol. 28 (1996) 495-505, http://dx.doi.org/10.1016/0735-1097(96) 00151-9.

[156] X. Cui, Z. Xie, Protein interaction and Na/K-ATPase-mediated signal transduction, Molecules (Basel Switzerland) 22 (2017), http://dx.doi.org/10.3390/ molecules22060990.

[157] F.A. Nezil, M. Bloom, Combined influence of cholesterol and synthetic amphiphillic peptides upon bilayer thickness in model membranes, Biophys. J. 61 (1992) 1176-1183, http://dx.doi.org/10.1016/S0006-3495(92)81926-4.

[158] F. Cornelius, Modulation of Na,K-ATPase and Na-ATPase activity by phospholipids and cholesterol. I. Steady-state kinetics, Biochemistry (Moscow) 40 (2001) 8842-8851.

[159] T. Shinoda, H. Ogawa, F. Cornelius, C. Toyoshima, Crystal structure of the sodiumpotassium pump at 2.4 A resolution, Nature 459 (2009) 446-450, http://dx.doi. org/10.1038/nature07939.

[160] R. Kanai, H. Ogawa, B. Vilsen, F. Cornelius, C. Toyoshima, Crystal structure of a $\mathrm{Na}+$-bound $\mathrm{Na}+, \mathrm{K}+$-ATPase preceding the E1P state, Nature 502 (2013) 201-206, http://dx.doi.org/10.1038/nature12578.

[161] E. Cohen, R. Goldshleger, A. Shainskaya, D.M. Tal, C. Ebel, M. le Maire, S.J.D. Karlish, Purification of $\mathrm{Na}+, \mathrm{K}+$-ATPase expressed in Pichia pastoris re veals an essential role of phospholipid-protein interactions, J. Biol. Chem. 280 (2005) 16610-16618, http://dx.doi.org/10.1074/jbc.M414290200.

[162] E. Kapri-Pardes, A. Katz, H. Haviv, Y. Mahmmoud, M. Ilan, I. Khalfin-Penigel, S. Carmeli, O. Yarden, S.J.D. Karlish, Stabilization of the $\alpha 2$ isoform of Na, KATPase by mutations in a phospholipid binding pocket, J. Biol. Chem. 286 (2011) 42888-42899, http://dx.doi.org/10.1074/jbc.M111.293852.

[163] H. Haviv, M. Habeck, R. Kanai, C. Toyoshima, S.J.D. Karlish, Neutral phospholipids stimulate Na, K-ATPase activity: a specific lipid-protein interaction, J. Biol. Chem. 288 (2013) 10073-10081, http://dx.doi.org/10.1074/jbc.M112.446997.

[164] M. Habeck, H. Haviv, A. Katz, E. Kapri-Pardes, S. Ayciriex, A. Shevchenko, H. Ogawa, C. Toyoshima, S.J.D. Karlish, Stimulation, inhibition, or stabilization of $\mathrm{Na}$, K-ATPase caused by specific lipid interactions at distinct sites, J. Biol. Chem. 290 (2015) 4829-4842, http://dx.doi.org/10.1074/jbc.M114.611384.

[165] M. Habeck, E. Kapri-Pardes, M. Sharon, S.J.D. Karlish, Specific phospholipid binding to Na, K-ATPase at two distinct sites, Proc. Natl. Acad. Sci. U.S.A. 114 (2017) 2904-2909, http://dx.doi.org/10.1073/pnas.1620799114.

[166] R. Rodrigo, J.P. Bächler, J. Araya, H. Prat, W. Passalacqua, Relationship between $(\mathrm{Na}+\mathrm{K})$-ATPase activity, lipid peroxidation and fatty acid profile in erythrocytes of hypertensive and normotensive subjects, Mol. Cell. Biochem. 303 (2007) 73-81, http://dx.doi.org/10.1007/s11010-007-9457-y.

[167] R. Rodrigo, A. Miranda-Merchak, R. Valenzuela Grau, J.P. Bachler, L. Vergara, Modulation of (Na, K)-ATPase activity by membrane fatty acid composition: therapeutic implications in human hypertension, Clin. Exp. Hypertens. 1993 (36) (2014) 17-26, http://dx.doi.org/10.3109/10641963.2013.783048.

[168] S. Iannello, P. Milazzo, F. Belfiore, Animal and human tissue Na,K-ATPase in normal and insulin-resistant states: regulation, behaviour and interpretative hypothesis on NEFA effects, Obes. Rev. Off. J. Int. Assoc. Study Obes. 8 (2007) 231-251, http://dx.doi.org/10.1111/j.1467-789X.2006.00276.x.

[169] S. Iannello, P. Milazzo, F. Belfiore, Animal and human tissue Na, K-ATPase in obesity and diabetes: a new proposed enzyme regulation, Am. J. Med. Sci. 333 (2007) 1-9.

[170] E.R. Chemaly, L. Troncone, D. Lebeche, SERCA control of cell death and survival, Cell Calcium (2017), http://dx.doi.org/10.1016/j.ceca.2017.07.001. 
[171] C. Toyoshima, Structural aspects of ion pumping by Ca2 +-ATPase of sarcoplasmic reticulum, Arch. Biochem. Biophys. 476 (2008) 3-11, http://dx.doi.org/10.1016/ j.abb.2008.04.017.

[172] Y. Norimatsu, K. Hasegawa, N. Shimizu, C. Toyoshima, Protein-phospholipid in terplay revealed with crystals of a calcium pump, Nature 545 (2017) 193-198, http://dx.doi.org/10.1038/nature22357.

[173] N.D. Drachmann, C. Olesen, J.V. Møller, Z. Guo, P. Nissen, M. Bublitz, Comparing crystal structures of $\mathrm{Ca}(2+)$-ATPase in the presence of different lipids, FEBS J. 281 (2014) 4249-4262, http://dx.doi.org/10.1111/febs.12957.

[174] K.H. Cheng, J.R. Lepock, S.W. Hui, P.L. Yeagle, The role of cholesterol in the activity of reconstituted Ca-ATPase vesicles containing unsaturated phosphatidylethanolamine, J. Biol. Chem. 261 (1986) 5081-5087.

[175] D.A. Los, N. Murata, Membrane fluidity and its roles in the perception of environmental signals, Biochim. Biophys. Acta 1666 (2004) 142-157, http://dx.doi. org/10.1016/j.bbamem.2004.08.002.

[176] C.E. Martin, C.-S. Oh, Y. Jiang, Regulation of long chain unsaturated fatty acid synthesis in yeast, Biochim. Biophys. Acta 1771 (2007) 271-285, http://dx.doi. org/10.1016/j.bbalip.2006.06.010.

[177] E. Saita, D. Albanesi, D. de Mendoza, Sensing membrane thickness: lessons learned from cold stress, Biochim. Biophys. Acta 2016 (1861) 837-846, http://dx.doi.org/ 10.1016/j.bbalip.2016.01.003.

[178] R. Ernst, C.S. Ejsing, B. Antonny, Homeoviscous adaptation and the regulation of membrane lipids, J. Mol. Biol. 428 (2016) 4776-4791, http://dx.doi.org/10. 1016/j.jmb.2016.08.013.

[179] D. de Mendoza, Temperature sensing by membranes, Annu. Rev. Microbiol. 68 (2014) 101-116, http://dx.doi.org/10.1146/annurev-micro-091313-103612.

[180] P. Sengupta, P. Garrity, Sensing temperature, Curr. Biol. 23 (2013) R304-R307, http://dx.doi.org/10.1016/j.cub.2013.03.009.

[181] C.S. Ejsing, J.L. Sampaio, V. Surendranath, E. Duchoslav, K. Ekroos, R.W. Klemm, K. Simons, A. Shevchenko, Global analysis of the yeast lipidome by quantitative shotgun mass spectrometry, Proc. Natl. Acad. Sci. 106 (2009) 2136-2141, http:// dx.doi.org/10.1073/pnas.0811700106.

[182] C. Klose, M.A. Surma, M.J. Gerl, F. Meyenhofer, A. Shevchenko, K. Simons, Flexibility of a eukaryotic lipidome - insights from yeast lipidomics, PLoS One 7 (2012) e35063, http://dx.doi.org/10.1371/journal.pone.0035063.

[183] S. Ballweg, R. Ernst, Control of membrane fluidity: the OLE pathway in focus, Biol. Chem. 398 (2016) 215-228, http://dx.doi.org/10.1515/hsz-2016-0277.

[184] D. Albanesi, M.C. Mansilla, D. de Mendoza, The membrane fluidity sensor DesK of Bacillus subtilis controls the signal decay of its cognate response regulator, J. Bacteriol. 186 (2004) 2655-2663, http://dx.doi.org/10.1128/JB.186.9.26552663.2004.

[185] L.E. Cybulski, G. del Solar, P.O. Craig, M. Espinosa, D. de Mendoza, Bacillus subtilis DesR functions as a phosphorylation-activated switch to control membrane lipid fluidity, J. Biol. Chem. 279 (2004) 39340-39347, http://dx.doi.org/10. 1074/jbc.M405150200.

[186] P.S. Aguilar, P. Lopez, D. de Mendoza, Transcriptional control of the low-temperature-inducible des Gene, encoding the $\Delta 5$ desaturase of Bacillus subtilis, J. Bacteriol. 181 (1999) 7028-7033.

[187] S.G. Altabe, P. Aguilar, G.M. Caballero, D. de Mendoza, The Bacillus subtilis acyl lipid desaturase is a $\Delta 5$ desaturase, J. Bacteriol. 185 (2003) 3228-3231, http://dx. doi.org/10.1128/JB.185.10.3228-3231.2003.

[188] A.R. Diaz, M.C. Mansilla, A.J. Vila, D. de Mendoza, Membrane topology of the acyl-lipid desaturase from Bacillus subtilis, J. Biol. Chem. 277 (2002) 48099-48106, http://dx.doi.org/10.1074/jbc.M208960200.

[189] H.J. Sharpe, T.J. Stevens, S. Munro, A comprehensive comparison of transmembrane domains reveals organelle-specific properties, Cell 142 (2010) 158-169, http://dx.doi.org/10.1016/j.cell.2010.05.037.

[190] R. Covino, S. Ballweg, C. Stordeur, J.B. Michaelis, K. Puth, F. Wernig, A. Bahrami, A.M. Ernst, G. Hummer, R. Ernst, A eukaryotic sensor for membrane lipid saturation, Mol. Cell. 63 (2016) 49-59, http://dx.doi.org/10.1016/j.molcel.2016. 05.015.

[191] T. Hoppe, K. Matuschewski, M. Rape, S. Schlenker, H.D. Ulrich, S. Jentsch, Activation of a membrane-bound transcription factor by regulated ubiquitin/ proteasome-dependent processing, Cell 102 (2000) 577-586, http://dx.doi.org/ 10.1016/S0092-8674(00)00080-5.

[192] E. Svensk, R. Devkota, M. Ståhlman, P. Ranji, M. Rauthan, F. Magnusson, S. Hammarsten, M. Johansson, J. Borén, M. Pilon, Caenorhabditis elegans PAQR-2 and IGLR-2 protect against glucose toxicity by modulating membrane lipid composition, PLoS Genet. 12 (2016) e1005982, http://dx.doi.org/10.1371/journal. pgen.1005982.

[193] M.R.V. Gilst, H. Hadjivassiliou, A. Jolly, K.R. Yamamoto, Nuclear hormone receptor NHR-49 controls fat consumption and fatty acid composition in C. elegans, PLoS Biol. 3 (2005) e53, http://dx.doi.org/10.1371/journal.pbio.0030053.

[194] P.P. Pathare, A. Lin, K.E. Bornfeldt, S. Taubert, M.R.V. Gilst, Coordinate regulation of lipid metabolism by novel nuclear receptor partnerships, PLoS Genet. 8 (2012) e1002645, http://dx.doi.org/10.1371/journal.pgen.1002645.

[195] A.K. Walker, R.L. Jacobs, J.L. Watts, V. Rottiers, K. Jiang, D.M. Finnegan, T. Shioda, M. Hansen, F. Yang, L.J. Niebergall, D.E. Vance, M. Tzoneva, A.C. Hart, A.M. Näär, A conserved SREBP-1/phosphatidylcholine feedback circuit regulates lipogenesis in metazoans, Cell 147 (2011) 840-852, http://dx.doi.org/10.1016/j. cell.2011.09.045.

[196] W.L. Holland, R.A. Miller, Z.V. Wang, K. Sun, B.M. Barth, H.H. Bui, K.E. Davis, B.T. Bikman, N. Halberg, J.M. Rutkowski, M.R. Wade, V.M. Tenorio, M.-S. Kuo, J.T. Brozinick, B.B. Zhang, M.J. Birnbaum, S.A. Summers, P.E. Scherer, Receptormediated activation of ceramidase activity initiates the pleiotropic actions of adiponectin, Nat. Med. 17 (2010) nm.2277, http://dx.doi.org/10.1038/nm.2277.
[197] H. Tanabe, Y. Fujii, M. Okada-Iwabu, M. Iwabu, Y. Nakamura, T. Hosaka, K. Motoyama, M. Ikeda, M. Wakiyama, T. Terada, N. Ohsawa, M. Hato, S. Ogasawara, T. Hino, T. Murata, S. Iwata, K. Hirata, Y. Kawano, M. Yamamoto, T. Kimura-Someya, M. Shirouzu, T. Yamauchi, T. Kadowaki, S. Yokoyama, Crystal structures of the human adiponectin receptors, Nature 520 (2015), http://dx.doi. org/10.1038/nature14301 nature14301.

[198] T. Yamauchi, J. Kamon, Y. Ito, A. Tsuchida, T. Yokomizo, S. Kita, T. Sugiyama, M. Miyagishi, K. Hara, M. Tsunoda, K. Murakami, T. Ohteki, S. Uchida,

S. Takekawa, H. Waki, N.H. Tsuno, Y. Shibata, Y. Terauchi, P. Froguel, K. Tobe, S. Koyasu, K. Taira, T. Kitamura, T. Shimizu, R. Nagai, T. Kadowaki, Cloning of adiponectin receptors that mediate antidiabetic metabolic effects, Nature 423 (2003), http://dx.doi.org/10.1038/nature01705 nature01705.

[199] S. Bernales, F.R. Papa, P. Walter, Intracellular signaling by the unfolded protein response, Annu. Rev. Cell Dev. Biol. 22 (2006) 487-508, http://dx.doi.org/10. 1146/annurev.cellbio.21.122303.120200.

[200] M.C. Jonikas, S.R. Collins, V. Denic, E. Oh, E.M. Quan, V. Schmid, J. Weibezahn, B. Schwappach, P. Walter, J.S. Weissman, M. Schuldiner, Comprehensive characterization of genes required for protein folding in the endoplasmic reticulum Science 323 (2009) 1693-1697, http://dx.doi.org/10.1126/science.1167983.

[201] K.J. Travers, C.K. Patil, L. Wodicka, D.J. Lockhart, J.S. Weissman, P. Walter, Functional and genomic analyses reveal an essential coordination between the unfolded protein response and ER-associated degradation, Cell 101 (2000) 249-258, http://dx.doi.org/10.1016/S0092-8674(00)80835-1.

[202] P. Walter, D. Ron, The unfolded protein response: from stress pathway to homeostatic regulation, Science 334 (2011) 1081-1086, http://dx.doi.org/10. 1126/science.1209038.

[203] K. Halbleib, K. Pesek, R. Covino, H.F. Hofbauer, D. Wunnicke, I. Hänelt, G. Hummer, R. Ernst, Activation of the unfolded protein response by lipid bilayer stress, Mol. Cell. 67 (2017), http://dx.doi.org/10.1016/j.molcel.2017.06.012 673-684.e8.

[204] K. Mori, Signalling pathways in the unfolded protein response: development from yeast to mammals, J. Biochem. (Tokyo) 146 (2009) 743-750, http://dx.doi.org/ $10.1093 / \mathrm{jb} / \mathrm{mvp} 166$.

[205] P. Fagone, R. Sriburi, C. Ward-Chapman, M. Frank, J. Wang, C. Gunter, J.W. Brewer, S. Jackowski, Phospholipid biosynthesis program underlying membrane expansion during B-lymphocyte differentiation, J. Biol. Chem. 282 (2007) 7591-7605, http://dx.doi.org/10.1074/jbc.M608175200.

[206] R. Sriburi, S. Jackowski, K. Mori, J.W. Brewer, XBP1: a link between the unfolded protein response, lipid biosynthesis, and biogenesis of the endoplasmic reticulum, J. Cell Biol. 167 (2004) 35-41, http://dx.doi.org/10.1083/jcb.200406136.

[207] R. Sriburi, H. Bommiasamy, G.L. Buldak, G.R. Robbins, M. Frank, S. Jackowski, J.W. Brewer, Coordinate regulation of phospholipid biosynthesis and secretory pathway gene expression in XBP-1(S)-induced endoplasmic reticulum biogenesis, J. Biol. Chem. 282 (2007) 7024-7034, http://dx.doi.org/10.1074/jbc. M609490200.

[208] A.-H. Lee, G.C. Chu, N.N. Iwakoshi, L.H. Glimcher, XBP-1 is required for biogenesis of cellular secretory machinery of exocrine glands, EMBO J. 24 (2005) 4368-4380, http://dx.doi.org/10.1038/sj.emboj.7600903.

[209] S. Schuck, W.A. Prinz, K.S. Thorn, C. Voss, P. Walter, Membrane expansion alleviates endoplasmic reticulum stress independently of the unfolded protein response, J. Cell Biol. 187 (2009) 525-536, http://dx.doi.org/10.1083/jcb. 200907074.

[210] R. Volmer, K. van der Ploeg, D. Ron, Membrane lipid saturation activates endoplasmic reticulum unfolded protein response transducers through their transmembrane domains, Proc. Natl. Acad. Sci. 110 (2013) 4628-4633, http://dx.doi. org/10.1073/pnas.1217611110.

[211] S. Han, M.A. Lone, R. Schneiter, A. Chang, Orm1 and Orm2 are conserved endoplasmic reticulum membrane proteins regulating lipid homeostasis and protein quality control, Proc. Natl. Acad. Sci. 107 (2010) 5851-5856, http://dx.doi.org/ 10.1073/pnas.0911617107.

[212] P. Lajoie, R.D. Moir, I.M. Willis, E.L. Snapp, Kar2p availability defines distinct forms of endoplasmic reticulum stress in living cells, Mol. Biol. Cell 23 (2012) 955-964, http://dx.doi.org/10.1091/mbc.E11-12-0995.

[213] L. Pineau, J. Colas, S. Dupont, L. Beney, P. Fleurat-Lessard, J.-M. Berjeaud, T. Bergès, T. Ferreira, Lipid-induced ER stress: synergistic effects of sterols and saturated fatty acids, Traffic 10 (2009) 673-690, http://dx.doi.org/10.1111/j. 1600-0854.2009.00903.x.

[214] T. Promlek, Y. Ishiwata-Kimata, M. Shido, M. Sakuramoto, K. Kohno, Y. Kimata, Membrane aberrancy and unfolded proteins activate the endoplasmic reticulum stress sensor Ire1 in different ways, Mol. Biol. Cell 22 (2011) 3520-3532, http:// dx.doi.org/10.1091/mbc.E11-04-0295.

[215] G. Thibault, G. Shui, W. Kim, G.C. McAlister, N. Ismail, S.P. Gygi, M.R. Wenk, D.T.W. Ng, The membrane stress response buffers lethal effects of lipid disequilibrium by reprogramming the protein homeostasis network, Mol. Cell 48 (2012) 16-27, http://dx.doi.org/10.1016/j.molcel.2012.08.016.

[216] M.F. Gregor, L. Yang, E. Fabbrini, B.S. Mohammed, J.C. Eagon, G.S. Hotamisligil, S. Klein, Endoplasmic reticulum stress is reduced in tissues of obese subjects after weight loss, Diabetes 58 (2009) 693-700, http://dx.doi.org/10.2337/db08-1220.

[217] K.H. Pietiläinen, T. Róg, T. Seppänen-Laakso, S. Virtue, P. Gopalacharyulu, J. Tang, S. Rodriguez-Cuenca, A. Maciejewski, J. Naukkarinen, A.-L. Ruskeepää, P.S. Niemelä, L. Yetukuri, C.Y. Tan, V. Velagapudi, S. Castillo, H. Nygren, T. Hyötyläinen, A. Rissanen, J. Kaprio, H. Yki-Järvinen, I. Vattulainen, A. VidalPuig, M. Orešič, Association of lipidome remodeling in the adipocyte membrane with acquired obesity in humans, PLoS Biol. 9 (2011), http://dx.doi.org/10.1371/ journal.pbio.1000623.

[218] T.P. Herbert, D.R. Laybutt, A Reevaluation of the role of the unfolded protein 
response in islet dysfunction: maladaptation or a failure to adapt? Diabetes 65 (2016) 1472-1480, http://dx.doi.org/10.2337/db15-1633.

[219] M. Rocha, N. Diaz-Morales, S. Rovira-Llopis, I. Escribano-Lopez, C. Bañuls, A. Hernandez-Mijares, E. Diamanti-Kandarakis, V.M. Victor, Mitochondrial dysfunction and endoplasmic reticulum stress in diabetes, Curr. Pharm. Des. 22 (2016) 2640-2649.

[220] D.L. Eizirik, A.K. Cardozo, M. Cnop, The role for endoplasmic reticulum stress in diabetes mellitus, Endocr. Rev. 29 (2008) 42-61, http://dx.doi.org/10.1210/er. 2007-0015.

[221] S.G. Fonseca, J. Gromada, F. Urano, Endoplasmic reticulum stress and pancreatic B-cell death, Trends Endocrinol. Metab. 22 (2011) 266-274, http://dx.doi.org/10. 1016/j.tem.2011.02.008.

[222] D. Scheuner, R.J. Kaufman, The Unfolded protein response: a pathway that links insulin demand with $\beta$-cell failure and diabetes, Endocr. Rev. 29 (2008) 317-333, http://dx.doi.org/10.1210/er.2007-0039.

[223] O. Soubias, W.E. Teague, K.G. Hines, K. Gawrisch, The role of membrane curvature elastic stress for function of rhodopsin-like $\mathrm{G}$ protein-coupled receptors, Biochimie 107 (Pt A) (2014) 28-32, http://dx.doi.org/10.1016/j.biochi.2014.10. 011.

[224] M. Arish, A. Husein, M. Kashif, P. Sandhu, S.E. Hasnain, Y. Akhter, A. Rub, Orchestration of membrane receptor signaling by membrane lipids, Biochimie 113 (2015) 111-124, http://dx.doi.org/10.1016/j.biochi.2015.04.005.

[225] D.B. Savage, C.S. Choi, V.T. Samuel, Z.-X. Liu, D. Zhang, A. Wang, X.-M. Zhang, G.W. Cline, X.X. Yu, J.G. Geisler, S. Bhanot, B.P. Monia, G.I. Shulman, Reversal of diet-induced hepatic steatosis and hepatic insulin resistance by antisense oligonucleotide inhibitors of acetyl-CoA carboxylases 1 and 2, J. Clin. Invest. 116 (2006) 817-824, http://dx.doi.org/10.1172/JCI27300.

[226] J.M. Ntambi, M. Miyazaki, J.P. Stoehr, H. Lan, C.M. Kendziorski, B.S. Yandell, Y. Song, P. Cohen, J.M. Friedman, A.D. Attie, Loss of stearoyl-CoA desaturase-1 function protects mice against adiposity, Proc. Natl. Acad. Sci. U.S.A. 99 (2002)
11482-11486, http://dx.doi.org/10.1073/pnas.132384699.

[227] J. Jacquemyn, A. Cascalho, R.E. Goodchild, The ins and outs of endoplasmic reticulum-controlled lipid biosynthesis, EMBO Rep. 18 (2017) 1905-1921, http:// dx.doi.org/10.15252/embr.201643426.

[228] S.L. Cassel, S. Joly, F.S. Sutterwala, The NLRP3 inflammasome: a sensor of immune danger signals, Semin. Immunol. 21 (2009) 194-198, http://dx.doi.org/10. 1016/j.smim.2009.05.002.

[229] B. Vandanmagsar, Y.-H. Youm, A. Ravussin, J.E. Galgani, K. Stadler, R.L. Mynatt, E. Ravussin, J.M. Stephens, V.D. Dixit, The NALP3/NLRP3 inflammasome instigates obesity-induced autoinflammation and insulin resistance, Nat. Med. 17 (2011) 179-188, http://dx.doi.org/10.1038/nm.2279.

[230] L. L'homme, N. Esser, L. Riva, A. Scheen, N. Paquot, J. Piette, S. Legrand-Poels, Unsaturated fatty acids prevent activation of NLRP3 inflammasome in human monocytes/macrophages, J. Lipid Res. 54 (2013) 2998-3008, http://dx.doi.org/ 10.1194/jlr.M037861.

[231] N. Esser, L. L'homme, A.D. Roover, L. Kohnen, A.J. Scheen, M. Moutschen, J. Piette, S. Legrand-Poels, N. Paquot, Obesity phenotype is related to NLRP3 inflammasome activity and immunological profile of visceral adipose tissue, Diabetologia 56 (2013) 2487-2497, http://dx.doi.org/10.1007/s00125-0133023-9.

[232] S. Legrand-Poels, N. Esser, L. L'Homme, A. Scheen, N. Paquot, J. Piette, Free fatty acids as modulators of the NLRP3 inflammasome in obesity/type 2 diabetes, Biochem. Pharmacol. (2014), http://dx.doi.org/10.1016/j.bcp.2014.08.013.

[233] N. Esser, S. Legrand-Poels, J. Piette, A.J. Scheen, N. Paquot, Inflammation as a link between obesity, metabolic syndrome and type 2 diabetes, Diabetes Res. Clin. Pract. 105 (2014) 141-150, http://dx.doi.org/10.1016/j.diabres.2014.04.006.

[234] M.M. Robblee, C.C. Kim, J.P. Abate, M. Valdearcos, K.L.M. Sandlund, M.K. Shenoy, R. Volmer, T. Iwawaki, S.K. Koliwad, Saturated fatty acids engage an IRE1 $\alpha$-dependent pathway to activate the NLRP3 inflammasome in myeloid cells, Cell Rep. 14 (2016) 2611-2623, http://dx.doi.org/10.1016/j.celrep.2016.02.053. 